\title{
Pandemia, gobernanza y municipalismo en las coronas metropolitanas a partir de su estudio en Riba-roja de Túria (València)
}

\author{
Pandemic, governance, and municipalism in the metropolitan crowns \\ based on its study in Riba-roja de Turia (Valencia)
}

\author{
Sandra Mayordomo Maya ${ }^{1^{*}}$ (iD) \\ Jorge Hermosilla $\mathrm{Pla}^{2}$ (iD \\ Mónica Fernández Villarejo ${ }^{3}$ (i)
}

\section{Resumen}

La crisis del COVID-19 ha impactado en el sistema sanitario de los territorios, pero también en sus ámbitos socioeconómicos, lo que ha requerido una respuesta eficaz por las autoridades. El objetivo de esta investigación es la identificación de las dinámicas generales derivadas de la pandemia en las áreas metropolitanas, a partir de un estudio local realizado en el municipio valenciano de Riba-roja de Túria. Se ha aplicado una metodología que combina el tratamiento de estadísticas y documentación técnica municipal, con información cualitativa obtenida mediante entrevistas con agentes locales. La crisis ha incidido en la totalidad de sectores, con un aumento de las desigualdades y la vulnerabilidad. El Ayuntamiento ha tenido un papel relevante en la gestión de la emergencia del coronavirus, con la implementación de medidas y la adopción de nuevos mecanismos de gobernanza. El carácter sistémico de la pandemia ha permitido detectar dinámicas y procesos comunes con otras áreas urbanas. En base a estos resultados, es posible proponer estrategias destinadas a conseguir modelos territoriales más resilientes.

Palabras clave: COVID-19; pandemia; Riba-roja de Túria; gobernanza; resiliencia territorial; áreas urbanas.

\begin{abstract}
The COVID-19 crisis has impacted on the regional health systems and their socioeconomic environments, and this has required an effective response by the authorities. This research identifies the general dynamics derived from the pandemic in metropolitan areas, based on a local study conducted in the Valencian municipality of Riba-roja de Túria. The methodology combines the processing of municipal statistics and technical documentation with qualitative information obtained through interviews with local agents. The crisis has affected all sectors and increased inequalities and vulnerability. The city council has played a role in the management of the coronavirus emergency with the implementation of new governance mechanisms. The systemic nature of the pandemic has made it possible to detect common dynamics and processes with other urban areas. Based on these results, it is possible to propose strategies for achieving more resilient territorial models.
\end{abstract}

Keywords: COVID-19; pandemic; Riba-roja de Túria; governance; territorial resilience; urban areas.

1 ESTEPA. Estudios del Territorio, Paisaje y Patrimonio. Departamento de Geografía, Universitat de València, España. sandra.mayordomo@ uv.es. * Autora para correspondencia

2 ESTEPA. Estudios del Territorio, Paisaje y Patrimonio. Departamento de Geografía, Universitat de València, España. jorge.hermosilla@uv.es

3 ESTEPA. Estudios del Territorio, Paisaje y Patrimonio. Departamento de Geografía, Universitat de València, España. monica.fernandezvillarejo@uv.es 


\section{Introducción}

El COVID-19 es una enfermedad infecciosa viral causada por el síndrome respiratorio agudo grave 2 o SARS-CoV-2, el séptimo coronavirus que puede propagarse entre los humanos (Andersen, Rambaut, Lipkin, Holmes y Garry, 2020). Se identificó por primera vez en el mes de diciembre de 2019 en la ciudad de Wuhan, en la provincia china de Hubei (Hui, et al., 2020). El 30 de enero de 2020, en base a la evolución de la situación de la enfermedad, y por recomendación del Comité de Emergencias del Reglamento Sanitario Internacional, el Director General de la Organización Mundial de la Salud (OMS) declaró el brote del nuevo coronavirus COVID-19 como una Emergencia de Salud Pública de Importancia Internacional (ESPII). Posteriormente, el 11 de marzo de 2020, este organismo lo calificó como pandemia debido a los alarmantes niveles de propagación registrados (Organización Mundial de la Salud [OMS], 2021). La rápida transmisión de la enfermedad y sus graves efectos sobre la salud de los seres humanos exigieron la adopción de estrictas y urgentes medidas de contención y aislamiento por parte de las autoridades. De este modo, las restricciones de movilidad y de uso del espacio público, el confinamiento y el distanciamiento social, se han configurado como disposiciones esenciales a nivel mundial para reducir la propagación del COVID-19 y proteger la salud pública (Honey-Rosés, et al., 2020).

El primer positivo de COVID-19 en España fue diagnosticado el 31 de enero de 2020. Ante la rápida expansión del virus y el acusado incremento de los contagios, el Gobierno español aprobó, mediante el Real Decreto 463/2020, de 14 de marzo, el estado de alarma para la gestión de la situación de crisis sanitaria ocasionada por el COVID-19 en la totalidad del territorio nacional, con un confinamiento de la población en sus lugares de residencia, y la implementación de medidas restrictivas de movilidad y actividad económica. Otros países también instauraron el confinamiento entre sus habitantes ante la incidencia de la crisis sanitaria, ya que el distanciamiento social es una eficaz medida no clínica para frenar el avance de la pandemia (Prem, et al., 2020). En este contexto, el Gobierno español aprobó el Real Decreto-ley 10/2020, de 29 de marzo, en el que se establece el cese de las actividades laborales presenciales consideradas no esenciales entre el 30 de marzo y el 9 de abril.

El estado de alarma se instauró inicialmente por un periodo de quince días naturales, pero debido a la situación epidemiológica, se efectuaron seis prórrogas. El 28 de abril, el Consejo de Ministros aprobó un plan de desescalada con el objetivo de recuperar el bienestar socioeconómico y abordar la transición hacia una nueva normalidad. El plan constaba de cuatro fases que posibilitarían la reducción gradual de las restricciones y el confinamiento. El 21 de junio finalizó el estado de alarma y comenzó la etapa denominada como "nueva normalidad", en la que terminaron las restricciones, pero continuó la vigilancia de la evolución epidemiológica, las medidas de autoprotección ciudadana, y el refuerzo del sistema y la asistencia sanitaria (Presidencia del Gobierno de España, 2020a).

En el periodo estival se produjeron numerosos rebrotes en España, por lo que algunos territorios establecieron restricciones para mitigar el impacto de la pandemia. Se registró una tendencia ascendente en el número de contagios y a finales de octubre se contabilizaron elevadas cifras de incidencia. En este contexto, el Gobierno aprobó, mediante el Real Decreto 926/2020, de 25 de octubre, el estado de alarma para contener la propagación de infecciones causadas por el SARS-CoV-2 en la totalidad del territorio nacional. Este estado finalizó el 9 de noviembre de 2020, pero el Consejo de Ministros aprobó una prórroga hasta el 9 de mayo de 2021, mediante el Real Decreto 956/2020. En este periodo no se estableció un confinamiento general de la ciudadanía, pero se implementó toque de queda nocturno y se determinaron otras limitaciones. Además, cada comunidad o ciudad autónoma podía modificar las medidas en función de la evolución del COVID-19 en su ámbito territorial. El 27 de diciembre comenzó la campaña de vacunación en España.

La pandemia del COVID-19 supone un significativo impacto en la sociedad y conlleva múltiples disrupciones en la totalidad de sectores. La propagación de los contagios y la afectación de la enfermedad provocan una profunda crisis en el sistema sanitario y en la salud pública, pero también en el ámbito económico y el social. No obstante, sus efectos se manifiestan de manera desigual en función de diferentes factores. Las áreas urbanas son las principales afectadas por el COVID-19 (Maza y Villarreal, 2020). Estos espacios concentran el $90 \%$ de los contagios registrados a nivel mundial (Naciones Unidas, 2020). La elevada densidad poblacional, los fluidos intercambios socioeconómicos, los modelos culturales y de relación social, o los sistemas de movilidad que caracterizan a las urbes, se convierten en la actualidad en aspectos facilitadores de la expansión del virus (Paisaje Transversal, 2020). De este modo, la crisis sanitaria 
es fundamentalmente urbana (González y Piñeira, 2020) y ha puesto de manifiesto las debilidades y vulnerabilidades de las ciudades, así como de sus modelos de desarrollo territorial. En este escenario de incertidumbre, la contingencia conforma un nuevo marco de descripción en las sociedades, donde los conceptos y teorías de desarrollo local deberán considerar y analizar conceptos emergentes, como el riesgo y el peligro (Pont-Vidal, 2020). Asimismo, la incidencia del COVID-19 muestra la importancia de adaptar las urbes del futuro hacia el modelo smart city. Actualmente, la tecnología se configura como una herramienta esencial para el diseño y desarrollo de las ciudades, así como para la consecución de espacios urbanos más resilientes. La transición digital se ha convertido en una prioridad mundial, y las políticas públicas deben incorporar estrategias smart, con objeto de mejorar el funcionamiento de las ciudades y aumentar la calidad de vida de sus habitantes (Rozga y Hernández, 2019). En este sentido, la pandemia motiva a cuestionar y replantear la planificación urbana y territorial desde nuevas perspectivas y estrategias, con el propósito de responder a las necesidades del COVID-19, y así disponer en el futuro de ciudades más resilientes, responsables y preparadas.

La gravedad de la crisis ha precisado una respuesta inmediata y eficaz por parte de la totalidad de los actores territoriales, en particular de las administraciones públicas. En este sentido, el Gobierno estatal español ha desarrollado medidas económicas extraordinarias y una amplia diversidad de ayudas, subvenciones y moratorias para gestionar las incidencias acontecidas. Según el estudio de Calviño (2020), la intervención de las autoridades, tanto nacionales como europeas, ha sido fundamental para el sostenimiento del tejido productivo durante la fase álgida de la pandemia en España, así como para la posterior recuperación. La referida publicación destaca algunas de las medidas implementadas por el Gobierno, como son la adopción del programa de avales públicos para garantizar la liquidez a las empresas, la flexibilización y apoyo a los Expedientes de Regulación Temporal de Empleo (ERTE), la prestación por cese de actividad para los trabajadores autónomos, así como otras acciones orientadas a ayudar a colectivos vulnerables, entre las que sobresale el establecimiento del Ingreso Mínimo Vital. Asimismo, el 7 de octubre de 2020 el Gobierno presentó el Plan de Recuperación, Transformación y Resiliencia. Este proyecto de país movilizará en los próximos tres años la mitad de los recursos con los que cuenta España merced al Fondo de Recuperación NextGeneration EU, un instrumento europeo temporal para hacer frente a las consecuencias socioeconómicas del COVID-19 (Presidencia del Gobierno de España, 2020b).

La reacción institucional y legal sobre la gestión del COVID-19 en España muestra el significativo esfuerzo realizado por la Administración central. Sin embargo, durante esta crisis se han observado relevantes carencias de gobernanza (Carnicero, 2020). Según Farinós (2005), el concepto de gobernanza presenta cuatro dimensiones principales: la participación pública (nivel local), la coordinación horizontal (entre políticas y entre territorios), el desarrollo económico, y la gobernanza multinivel. Se trata de una forma participativa de gobierno, que promulga una mayor coordinación entre actores y niveles, enfocándose en la búsqueda de alternativas a la organización jerárquica (Bao y Delgado, 2020). La singularidad de la gobernanza "territorial" radica en que su objeto es el desarrollo del territorio, entendido como construcción social, soporte y resultado de las diferentes actuaciones y políticas (Farinós y González, 2020). Es un proceso de organización de las relaciones entre actores e intereses presentes en el territorio, cuyo resultado es la visión territorial compartida, necesaria para alcanzar la cohesión sostenible en la totalidad de niveles (Farinós, 2008).

La pandemia se ha convertido en un indicativo de que las capacidades de gobernanza en los diferentes niveles de gobierno no responden adecuadamente a emergencias globales complejas (United Cities and Local Governments [UCLG], Metropolis y LSE Cities, 2020). En este sentido, y de acuerdo con Romero (2020), la gestión de la pandemia en España no ha sido suficiente para comprender que los procesos de toma de decisiones deben fundamentarse en la gobernanza compartida. Por ejemplo, el funcionamiento de las Conferencias de Presidentes se ha basado en dar a conocer los anuncios efectuados por el presidente del Gobierno a los representantes autonómicos, sin discutir previamente con ellos las acciones que debían establecerse. Los estilos de gobierno y el diseño de políticas públicas, pese a la crisis, continúan estando muy alejados de la idea federal, y el modelo de gobernanza multinivel sigue siendo desordenado. El actual estado autonómico español presenta problemas de cooperación y coordinación institucional (Romero, 2006). Por ello, en la nueva normalidad socioeconómica es esencial avanzar en materia de coherencia, cohesión y gobernanza territorial. Igualmente, Alburquerque (2020) señala la necesidad de mejorar la participación efectiva de los actores territoriales clave. La colaboración entre estos agentes resulta imprescindible para hacer frente a la pandemia. El liderazgo no debe ser resultado de un mando 
unilateral o vertical, por lo que es fundamental una mayor coordinación entre los componentes del proceso de gobierno, promover la coherencia de las medidas en la totalidad de los niveles de la gobernanza, así como progresar en la conformación de instituciones de gobernanza participativa.

Las administraciones públicas autonómicas y locales han desarrollado, en sus respectivos ámbitos competenciales, medidas complementarias a las establecidas por el Gobierno central para paliar las repercusiones de la crisis. Las entidades municipales, como administraciones más próximas a la ciudadanía, implementan actuaciones concretas y adaptadas a la realidad territorial de cada localidad, con objeto de gestionar de manera eficiente las problemáticas derivadas de la pandemia. Estas autoridades poseen atribuciones de gobernanza y formulación normativa, y realizan una significativa labor en el ciclo de gestión de las emergencias, desde la preparación para la respuesta al COVID-19 hasta su recuperación (OMS, 2020). Los gobiernos locales tienen un papel cada vez más relevante en la toma de decisiones para la gestión de las emergencias globales, y presentan características clave para dar respuesta a este tipo de situaciones de riesgo: la proximidad con la sociedad civil, el conocimiento del territorio, y una mayor facilidad para adoptar perspectivas transversales y a diferentes escalas (Martí-Costa, Barres y Termes, 2020). Sin embargo, la interacción de los gobiernos locales con las administraciones superiores es mejorable. Es necesario reforzar el municipalismo frente a la pandemia, así como poner en valor su trascendental función en la gestión de la actual coyuntura, pues es un aspecto esencial para la vertebración territorial.

Las administraciones locales han aumentado el número y frecuencia de sus servicios como consecuencia del COVID-19, lo que conlleva la necesidad de disponer de mayores recursos para su financiación (López, 2020). El 2 de abril de 2020, la Federación Española de Municipios y Provincias (FEMP) propuso al Gobierno la aprobación de 19 medidas extraordinarias para asegurar una reactivación económica y laboral local (Federación Española de Municipios y Provincias [FEMP], 2020). La propuesta pretende involucrar a las entidades municipales y fomentar su participación activa en la actual coyuntura. Entre las medidas sugeridas destacan el uso de los superávits presupuestarios, la flexibilización de la regla de gasto, o el aumento del ámbito competencial (Analistas Financieros Internacionales, 2020). En este sentido, el 3 de agosto de 2020, la FEMP y el Ministerio de Hacienda aprobaron un acuerdo para que los ayuntamientos puedan disponer de sus superávits acumulados en los últimos años. Asimismo, el Gobierno acordó la suspensión de las reglas fiscales para los años 2020 y 2021, así como la elevación del techo de gasto.

A partir de estas reflexiones y antecedentes, la hipótesis de esta investigación se centra en que las administraciones públicas locales, como entidades más próximas a la sociedad, son agentes esenciales en la respuesta a la crisis, por lo que las acciones y servicios municipales resultan fundamentales para la mitigación de las incidencias acontecidas. En este estudio se analiza el impacto de la pandemia en la localidad valenciana de Riba-roja de Túria. Se trata de un municipio situado en un enclave estratégico de la segunda corona del Área Metropolitana de Valencia (AMV), caracterizado por un potente sector logístico y la presencia de significativos recursos territoriales. El Ayuntamiento ha impulsado la actualización de su Plan Estratégico Participado (Hermosilla, Morales, González y Mayordomo, 2018), con el propósito de adaptarlo a las nuevas circunstancias derivadas del COVID-19 y conocer sus efectos en la gestión municipal. En este sentido, se efectúa un análisis de la gobernanza del Consistorio ante la crisis, así como de las medidas y cambios organizativos y relacionales que ha implementado para afrontarla.

En el territorio valenciano existen diversas investigaciones que analizan las incidencias socioeconómicas ocasionadas por la pandemia en ámbitos determinados, tanto a nivel local como supramunicipal. En este sentido destaca el trabajo de Espí (2020), que expone los impactos registrados del COVID-19 entre los meses de marzo y junio en la localidad alicantina de Los Montesinos; o el de Hermosilla (2021), en el que los Pactos y Acuerdos por el Empleo de la Comunitat Valenciana estudian los efectos de la actual situación en sus respectivos territorios. Sin embargo, no se tiene constancia de ningún municipio valenciano, con excepción de Riba-roja de Túria, que disponga de un Plan Estratégico y haya decidido actualizar su diagnóstico y estrategias para realizar un seguimiento adaptado al contexto de la crisis sanitaria.

En consecuencia, el objetivo de esta investigación es identificar los procesos socioeconómicos generales derivados de la pandemia a partir del mencionado caso de estudio y, de esta manera, poder plantear acciones dirigidas a paliar sus incidencias y conseguir territorios más resilientes. De este modo, aunque el impacto del COVID-19 varía en función de distintos factores y ámbitos, la crisis actúa de manera global y sistémica, por lo que el análisis de las principales dinámicas acontecidas en Riba-roja de Túria permite detectar procesos compartidos con territorios de características semejantes. 


\section{Metodología}

\section{1. Área de estudio}

El municipio de Riba-roja de Túria se localiza en el sector meridional de la comarca valenciana del Camp de Túria, unos 20 kilómetros al oeste de la ciudad de Valencia. Esta región ha registrado relevantes transformaciones socioeconómicas en las últimas décadas, derivadas de la descentralización y expansión de la capital provincial y su entorno urbano. Los procesos económicos y demográficos se han dispersado sobre el territorio, de modo que Riba-roja de Túria y su comarca están integradas actualmente en la segunda corona de desarrollo del AMV. En este sentido, el municipio ha perdido progresivamente su tradicional fisonomía agraria y se ha convertido en un espacio dinámico y atractivo, con una significativa industrialización y terciarización de su economía (Hermosilla, et al., 2018). La Figura 1 muestra la localización del área de estudio, en la que se representa además la ubicación de sus principales recursos naturales y agrarios, así como su poblamiento, infraestructuras viarias y áreas industriales.

Figura 1. Localización del área de estudio
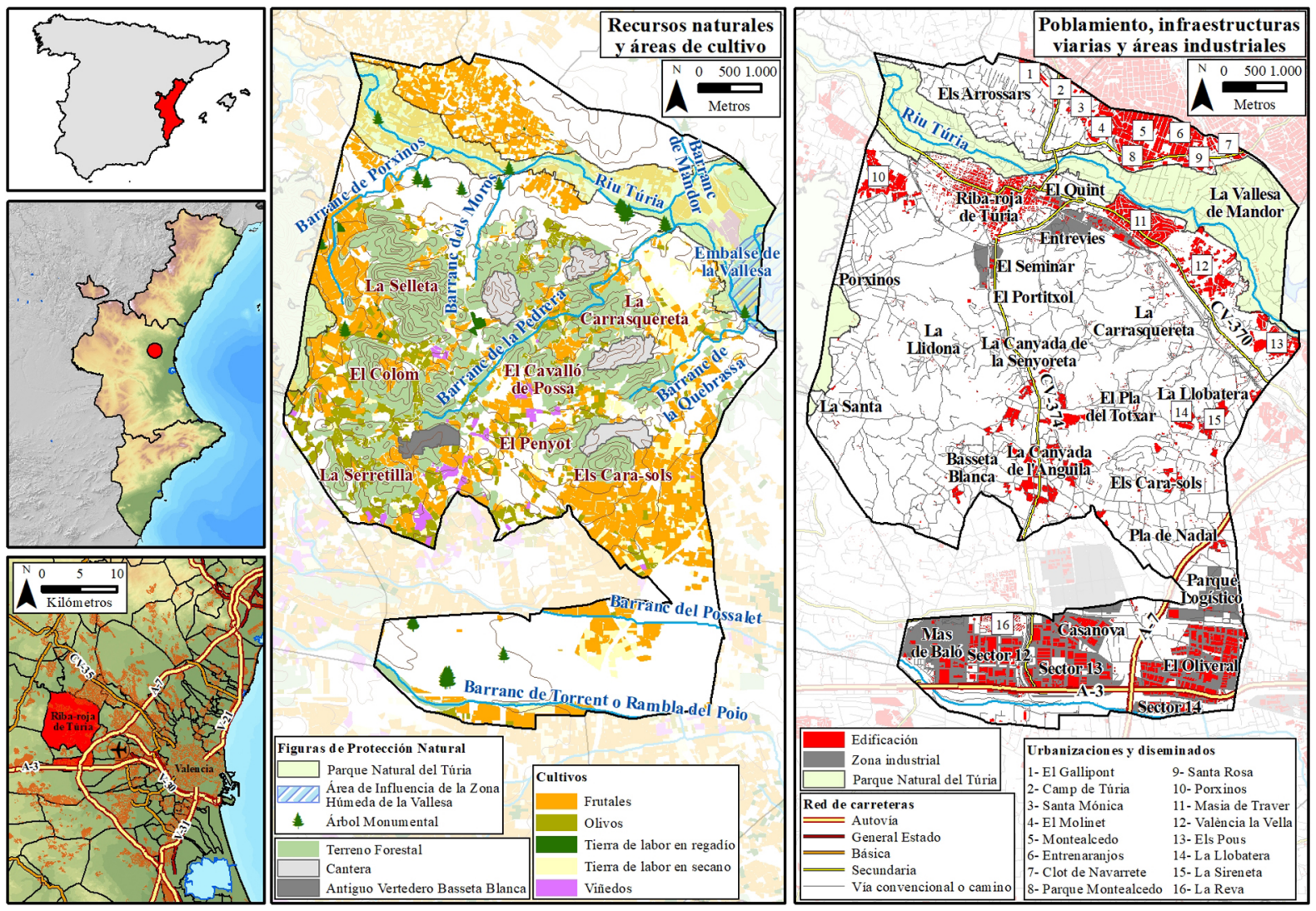

Fuente: Instituto Geográfico Nacional (IGN) e Institut Cartogràfic Valencià (ICV). Elaboración propia

El término posee una altitud media de 125 metros y está dividido por un suave anticlinal conformado por diversos cerros. Al norte de esta alineación se extiende la vega del río Túria. Este curso fluvial recorre el sector septentrional del municipio y sus aportes han conformado una fértil llanura sobre la que se extiende la huerta tradicional y el núcleo poblacional. En el año 2007 se aprobó la declaración del Parque Natural del Túria, que se centra especialmente en el cauce y riberas del río Túria, y constituye un interesante atractivo turístico. Otros espacios naturales protegidos son la Zona Húmeda del Embalse de la Vallesa y el arbolado monumental, con 46 ejemplares catalogados (Morales, Morales, Barberá y Herreros, 2020). Los terrenos forestales representan una quinta parte del territorio, en los que destacan los bosques de coníferas (Hermosilla y Membrado, 2018). La superficie cultivada ha experimentado un significativo retroceso, con un descenso del 45,2\% entre los años 2002 (3.254 hectáreas) y 2019 (1.783 hectáreas) (Conselleria d'Economia Sostenible, Sectors Productius, Comerç i Treball, 2021). Las tierras de secano han tenido una acentuada regresión, mientras que se ha producido la expansión de los regadíos. Los 
cultivos más numerosos son los cítricos, en particular el naranjo y el mandarino. También resulta reseñable el algarrobo (Conselleria d'Agricultura, Desenvolupament Rural, Emergència Climàtica i Transició Ecològica, 2021).

La localidad ha registrado un incremento demográfico desde los años 70 del siglo XX debido a la desconcentración urbana del AMV, y se ha producido una relevante expansión de entidades residenciales, algunas asociadas a segundas residencias. En el año 1970 la población de Riba-roja de Túria ascendía a 7.058 habitantes (Jordán y Sorribes, 1994) y en la actualidad el municipio cuenta con 23.941 habitantes, de los que el 61\% residen en el núcleo poblacional (Ayuntamiento de Riba-roja de Túria, 2021b). El casco urbano y las principales urbanizaciones se localizan en el sector septentrional del término, en las proximidades del río Túria. En el aspecto social sobresale la presencia de más de un centenar de asociaciones. Asimismo, el término posee interesantes recursos patrimoniales y una adecuada dotación de servicios y equipamientos.

En el último medio siglo se ha producido un significativo proceso de terciarización de la economía. El municipio está situado en una localización estratégica. En su sector meridional se emplaza la confluencia de la autovía A-3 y el By-Pass, tramo de la A-7 que circunvala la primera corona del AMV. En esta área se encuentran los principales polígonos industriales de Riba-roja de Túria, con 6,5 millones de metros cuadrados de suelo industrial. Constituye una zona muy atractiva para las empresas, con la presencia de excelentes comunicaciones viarias, y próxima al aeropuerto y puerto de Valencia. La logística es la actividad más destacada, aunque hay empresas de distinta tipología. El pequeño comercio se localiza fundamentalmente en el casco urbano.

\subsection{Método de trabajo}

El proceso de investigación desarrollado para la identificación de los procesos socioeconómicos derivados de la pandemia en Riba-roja de Túria está basado en la metodología utilizada en la citada publicación de Hermosilla (2021). Este trabajo expone el método implementado por los Pactos y Acuerdos por el Empleo valencianos con la finalidad de incorporar los efectos de la crisis en sus respectivos informes de Estrategias Territoriales. Las tareas propuestas en el referido estudio se fundamentan en la recogida de información estadística y en el desarrollo de procesos participativos mediante la realización de entrevistas a actores territoriales. En este sentido, y como consecuencia de los satisfactorios resultados de la mencionada publicación, en esta investigación se combina el tratamiento de datos estadísticos con información cualitativa obtenida a través de la participación de agentes locales clave.

Asimismo, con objeto de obtener una información pormenorizada de la gestión municipal ante la incidencia de la pandemia, y como documentación de apoyo a las entrevistas, se solicitaron informes técnicos a las concejalías y delegaciones del Ayuntamiento de Riba-roja de Túria. Esta tarea se ha inspirado en el estudio de Espí (2020), en el que se recopilan datos e informaciones proporcionadas por el equipo de gobierno y el personal del Ayuntamiento de Los Montesinos, para analizar los efectos de la pandemia en este territorio. Por tanto, el método de trabajo implementado se fundamenta en las metodologías utilizadas en las referidas publicaciones, pero de manera adaptada a las singularidades y particularidades de Riba-roja de Túria. Las acciones se detallan seguidamente, para las que se señalan las fuentes, criterios y procedimientos de análisis empleados.

a) Tratamiento de información estadística y consulta de fuentes bibliográficas. Se analizan datos y documentación disponible actualizada en materia sanitaria, económica, laboral, social o medioambiental, así como de otros sectores, que permiten identificar los procesos y dinámicas generadas por el COVID-19 en el municipio de estudio. Las principales fuentes consultadas son las estadísticas del Servei Valencià d'Ocupació i Formació (LABORA) (Servei Valencià d'Ocupació i Formació [LABORA], 2021a, 2021b); los datos sobre coronavirus ofrecidos por el portal de la Conselleria de Sanitat Universal i Salut Pública (Conselleria de Sanitat Universal i Salut Pública, 2021); así como la página web del Ayuntamiento de Riba-roja de Túria, en particular la información ofrecida en la sección de noticias (Ayuntamiento de Riba-roja de Túria, 2021a).

b) Obtención de información cualitativa mediante la realización de entrevistas semiestructuradas a actores clave del municipio. La participación y la interacción con los principales agentes implicados resulta esencial en la identificación de las dinámicas derivadas de la pandemia en Riba-roja de Túria. Se efectuaron 32 reuniones en las que se entrevistaron a 49 actores territoriales durante los meses de 
noviembre y diciembre de 2020, y en enero de 2021. Se trata de agentes que han sido seleccionados por sus amplios conocimientos sobre la realidad territorial, especialistas en distintos sectores socioeconómicos en la localidad. En este sentido, se han efectuado reuniones con los responsables políticos de cada área municipal y su personal técnico, dada la relevancia de la actuación de la Administración Pública local ante la pandemia. Asimismo, se ha consultado a actores representativos de los ámbitos económico, social, formativo y medioambiental de Riba-roja de Túria. La Tabla 1 detalla la relación de entidades entrevistadas agrupadas según el sector considerado, y el número de asistentes para cada conjunto. Se ha asignado un código a cada reunión mantenida, para su posterior identificación.

Tabla 1. Organismos y entidades entrevistadas

\begin{tabular}{|c|c|c|}
\hline $\begin{array}{c}\text { Códigos } \\
\text { reuniones }\end{array}$ & Tipología de organismos y entidades entrevistadas & $\begin{array}{c}\text { Número de } \\
\text { entrevistados }\end{array}$ \\
\hline \multicolumn{3}{|c|}{ A) Acción de gobierno: responsables políticos y personal técnico } \\
\hline $\mathrm{Al}$ & $\begin{array}{l}\text { Concejalía de Planificación Urbanística, Obras Públicas y Servicios } \\
\text { Municipales }\end{array}$ & 1 \\
\hline $\mathrm{A} 2$ & $\begin{array}{l}\text { Concejalía de Comercio, Sostenibilidad, Transición Ecológica, Economía } \\
\text { Circular y Agricultura }\end{array}$ & 4 \\
\hline A3 & Concejalía de Educación, Cultura, Infancia y Adolescencia & 1 \\
\hline A4 & $\begin{array}{l}\text { Concejalía de Hacienda, Contratación Pública, Patrimonio e Inventario, } \\
\text { Edificios Públicos e Infraestructuras, Actividades y Fomento Económico }\end{array}$ & 1 \\
\hline A5 & $\begin{array}{l}\text { Concejalía de Recursos Humanos, Seguridad Pública y Policía Local, } \\
\text { Servicios Generales, Régimen Jurídico, Innovación Tecnológica y } \\
\text { Administración Electrónica, Comunicación y Bienestar Animal }\end{array}$ & 1 \\
\hline A6 & Concejalía de Igualdad, Políticas Inclusivas y Derechos Sociales y Mayores & 1 \\
\hline A7 & Concejalía de Fiestas, Fallas y Juventud & 3 \\
\hline A8 & $\begin{array}{l}\text { Concejalía de Barrios y Urbanizaciones, Parques y Jardines, Servicios } \\
\text { Públicos y Transporte y Movilidad }\end{array}$ & 3 \\
\hline A9 & $\begin{array}{l}\text { Concejalía de Transparencia, Gobierno Abierto, Participación Ciudadana, } \\
\text { Turismo y Patrimonio Histórico }\end{array}$ & 2 \\
\hline Alo & Concejalía de Promoción de la Salud y Deportes & 4 \\
\hline Al1-A13 & Restantes partidos de la Corporación Municipal & 3 \\
\hline \multicolumn{3}{|c|}{ B) Dimensión económica } \\
\hline B1-B2 & Asociaciones locales empresariales industriales & 2 \\
\hline B3 & Asociación comercio local & 1 \\
\hline B4 & Asociación hostelería local & 2 \\
\hline B5 & Centro de Empleo LABORA & 1 \\
\hline \multicolumn{3}{|c|}{ C) Dimensión social } \\
\hline $\mathrm{Cl}-\mathrm{C} 3$ & Sindicatos & 3 \\
\hline C4 & Cáritas Riba-roja & 1 \\
\hline \multicolumn{3}{|c|}{ D) Formación y educación } \\
\hline D1-D8 & Centros educativos: públicos y concertados & 9 \\
\hline \multicolumn{3}{|c|}{ E) Medioambiente } \\
\hline E1 & AVA Consell Agrari y Comunidad de regantes & 2 \\
\hline E2 & Coordinadora en Defensa de los Bosques del Turia & 4 \\
\hline & Total & 49 \\
\hline
\end{tabular}

Elaboración propia 
Las entrevistas se realizaron mediante videoconferencia debido a las restricciones establecidas. La duración aproximada de cada reunión osciló entre una y dos horas. La entrevista comprende una decena de cuestiones abiertas, referidas a los siguientes aspectos: impactos generados por la crisis en el municipio, y específicamente en el sector del que es especialista cada entrevistado, medidas desarrolladas por la Administración pública y otras entidades locales para paliar la incidencia de la pandemia, valoración de las acciones implementadas, planteamientos previstos, y otras actuaciones que el agente entrevistado considera necesarias para resolver o paliar los efectos del COVID-19 en el futuro. Asimismo, en las entrevistas se plantearon cuestiones específicas de diferentes temáticas en función de la especialidad de cada informante. La realización de encuestas se ha desestimado en este estudio como consecuencia de las limitaciones derivadas de las actuales circunstancias.

c) Análisis de los informes técnicos proporcionados por el Ayuntamiento de Riba-roja de Túria. Con el propósito de conocer el impacto de la crisis en la gestión municipal y en los diferentes ámbitos del municipio, se solicitaron informes técnicos a cada concejalía y delegación del Consistorio. La información que se requirió para cada informe fue la siguiente: efectos y procesos generados por la crisis en el área correspondiente, principales cambios detectados, valoración técnica de la situación, y las medidas y acciones adoptadas ante las circunstancias sobrevenidas. En la medida de lo posible, la información aportada debía estar avalada por datos estadísticos. El personal técnico del Ayuntamiento mostró una significativa participación, ya que se elaboraron 26 informes municipales. No obstante, algunas áreas no remitieron ningún documento. Los contenidos aportados se clasificaron según los sectores y temáticas a los que hacen referencia (sanitaria, social o económica), y se integraron con el resto de información cuantitativa y cualitativa analizada. La Tabla 2 muestra la relación de los informes técnicos proporcionados y la delegación o concejalía que los ha efectuado. Se ha asignado un código a cada una de estas áreas municipales para su posterior identificación en este estudio.

Tabla 2. Relación de informes técnicos remitidos por el Ayuntamiento de Riba-roja de Túria

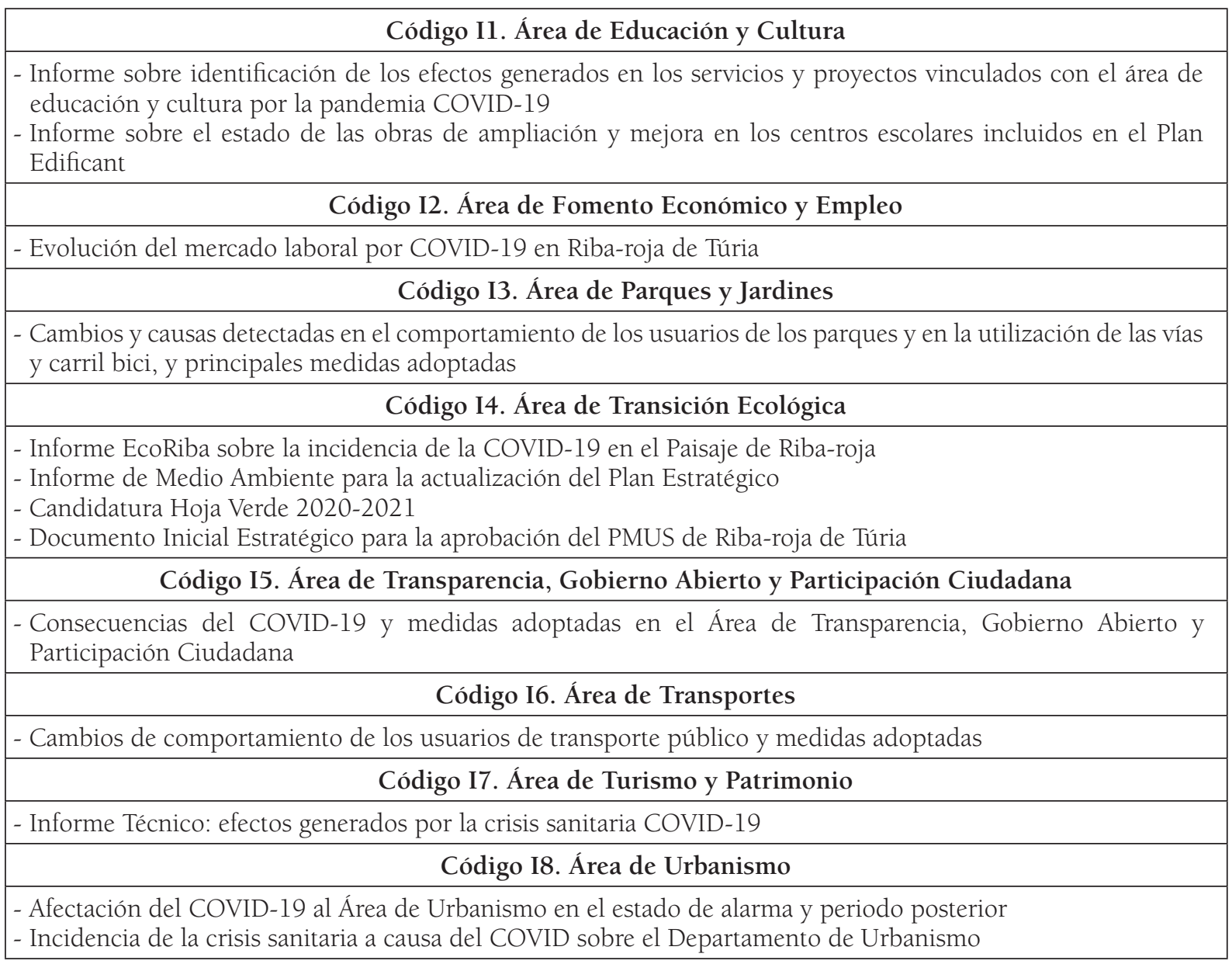




\begin{tabular}{|c|}
\hline Código 19. Área Políticas Inclusivas, Derechos Sociales y Mayores \\
\hline - Informe de competencias y actuaciones del área de políticas inclusivas y derechos sociales \\
\hline Código I10. Concejalía de Juventud \\
\hline - Principales impactos del COVID-19 y medidas adoptadas en el Área de Juventud \\
\hline Código Il1. Concejalía de la Mujer e Igualdad \\
\hline $\begin{array}{l}\text { - Consecuencias de la pandemia en los casos de violencia de género y medidas adoptadas } \\
\text { - Información sobre atención psicológica durante el Estado de Alarma }\end{array}$ \\
\hline Código I12. Oficina Municipal de Información al Consumidor y Servicios Públicos \\
\hline $\begin{array}{l}\text { - Procesos y medidas generadas por el impacto del COVID-19 en la Oficina Municipal de Información al } \\
\text { Consumidor }\end{array}$ \\
\hline Código I13. Padrón Municipal \\
\hline $\begin{array}{l}\text { - Estadística de la distribución de la población según su edad y sexo, agrupados por entidades, núcleos, distritos, } \\
\text { secciones y total de municipio Tres informes diferenciados para los meses de marzo y julio de 2020, y enero } \\
\text { de } 2021 \\
\text { - Movimientos demográficos anuales: nacimientos y defunciones. Datos: desde } 1996 \text { a } 2020\end{array}$ \\
\hline Código I14. Policía Local \\
\hline $\begin{array}{l}\text { - Mejoras en las plazas de estacionamiento para personas con movilidad reducida, según orden VIV/561/2010, } \\
\text { de } 1 \text { de febrero del Ministerio de Vivienda } \\
\text { - Plano de localización de las zonas de aparcamiento del casco urbano } \\
\text { - Previsión de plazas de estacionamientos en casco urbano } \\
\text { - Cuestionarios y datos estadísticos de la Policía Local } 2019 \text { y } 2020\end{array}$ \\
\hline
\end{tabular}

Elaboración propia

\section{Resultados}

La pandemia del COVID-19 supone efectos devastadores en la totalidad de sectores, y ha provocado una profunda crisis a nivel mundial en los ámbitos sanitario, social y económico. El proceso de investigación desarrollado ha permitido identificar y analizar los procesos e impactos derivados de la pandemia en Riba-roja de Túria. En los siguientes apartados se abordan los principales efectos de la crisis y se exponen las reacciones surgidas para hacer frente a esta situación, tanto desde el punto de vista institucional por parte del Ayuntamiento, como desde la sociedad local. Con el propósito de refrendar aquellos resultados obtenidos a partir de la consulta de los informes técnicos y/o de las entrevistas efectuadas, en el presente apartado se indican los respectivos códigos asignados en las tablas previas. La Figura 7, situada al final del epígrafe, plasma en un diagrama de conjunto los principales procesos derivados de la pandemia en Riba-roja de Túria y las interconexiones existentes.

\subsection{Crisis sanitaria}

El municipio de Riba-roja de Túria está adscrito al Departamento de Salud de Manises. Este ente cubre la demanda sanitaria de 207.000 personas residentes en 14 localidades valencianas. La Figura 2 representa la tasa de defunción y el número de PCR positivos registrados en los municipios del referido Departamento y otras áreas colindantes, según los datos de la Conselleria de Sanitat Universal i Salut Pública (2021), desde el inicio de la pandemia hasta el 30 de septiembre de 2021. Se observa un elevado número de contagios en ciudades del AMV, principalmente en la capital provincial (94.016) y en las cabeceras comarcales de l'Horta Nord (Paterna, con 8.619) y l'Horta Sud (Torrent, con 6.396). En el término de Riba-roja de Túria se han contabilizado 1.766 contagios y 29 fallecidos, lo que representa una tasa de defunción por 100.000 habitantes de 127,41. Esta tasa es inferior a la de su Departamento Sanitario, que se sitúa en 144,99, con 19.197 PCR+ y 298 fallecidos. Otros municipios de la segunda corona metropolitana valenciana con similares características socioeconómicas son Bétera, Cheste, LEliana, o Llíria, que registran mayores tasas de defunción que Riba-roja (166,64; 217,52; 185,17; y 187,38 respectivamente). La campaña de vacunación aporta esperanza a la ciudadanía. Sin embargo, la sensación de incertidumbre continúa presente (A10). 
Figura 2. Tasa de defunción por COVID-19 y número de PCR positivos en los municipios del Departamento Sanitario de Manises y áreas colindantes hasta el 30 de septiembre de 2021
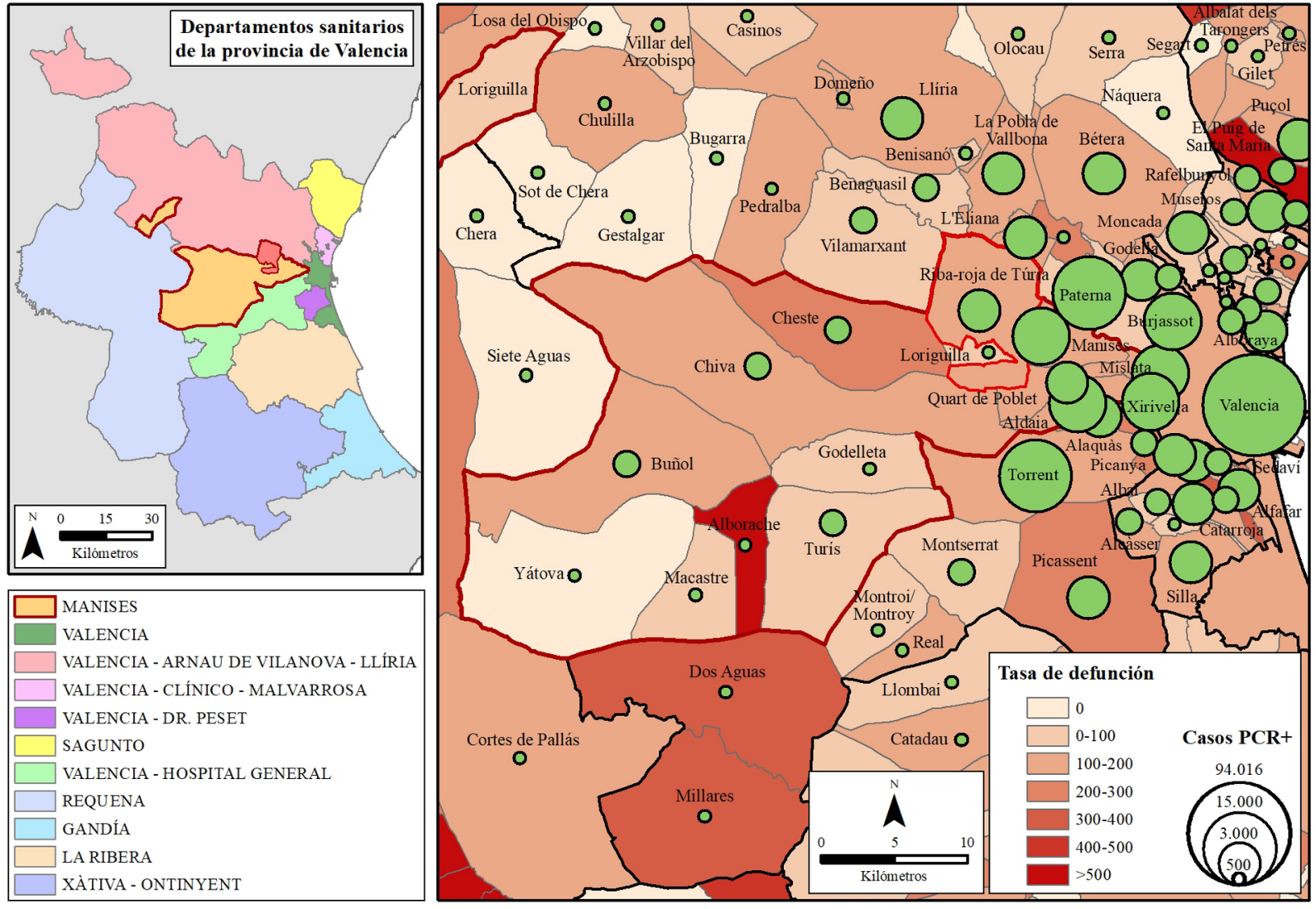

Fuente: Conselleria de Sanitat Universal i Salut Pública e Institut Cartogràfic Valencià (ICV). Elaboración propia

\subsubsection{Cierre del centro de salud}

El municipio posee un centro de salud edificado en 2002. El Gobierno local reclama desde hace diversos años su ampliación y una mayor dotación de recursos humanos sanitarios, debido a las crecientes demandas y el progresivo aumento poblacional producido en las últimas décadas (A1, A10, I8). Estas carencias se han acentuado como consecuencia de la incidencia del COVID-19 en la localidad. Durante los primeros meses de la pandemia se produce el cierre del centro de salud y la cancelación de la atención médica presencial por exigencia del protocolo de la Generalitat Valenciana. En consecuencia, en este periodo únicamente se atendía a la ciudadanía mediante consulta telefónica, lo que generó colapsos de llamadas, un significativo malestar entre la población, así como una sobrecarga de trabajo para los sanitarios (A10). Con el propósito de solventar estas problemáticas y mejorar la atención a los usuarios, el Departamento de Salud de Manises asignó cinco nuevos profesionales sanitarios al centro. Además, habilitó un "Call Center" desde el Hospital de Manises, con objeto de responder a las necesidades de los habitantes (Ayuntamiento de Riba-roja de Túria, 2021a).

\subsubsection{Medidas sanitarias}

El Área de Sanidad del Ayuntamiento ha desarrollado diversas actuaciones para paliar la incidencia de la pandemia, tal y como se ha señalado en la entrevista mantenida con esta delegación (A10). La actividad del centro de salud depende de la Conselleria, por lo que las acciones del Consistorio en el sector sanitario ante la crisis se han focalizado en ofrecer una labor informativa y de respuesta a peticiones. La transversalidad de este ámbito conllevó una coordinación continua con el resto de delegaciones municipales. Durante el confinamiento, las medidas implementadas por el Ayuntamiento se fundamentaron en la realización de campañas informativas sobre las novedades relacionadas con la pandemia, la donación de diversos pulsioxímetros al centro de salud, la habilitación de nuevas líneas 
telefónicas para permitir una mayor atención a los usuarios, la instalación de carpas para la atención a pacientes, así como la puesta en marcha de un servicio de recogida y entrega a domicilio de medicamentos y mascarillas a colectivos dependientes (A10).

\subsection{Crisis social}

La incidencia de la pandemia ha supuesto la pérdida de numerosos puestos de trabajo y la caída de los ingresos, lo que ha conllevado un incremento de la pobreza, de las desigualdades existentes, y del grado de dependencia de numerosas familias de Riba-roja de Túria (A6, B5, C1-C4, I2, I9). En el periodo de confinamiento se cerraron los centros educativos y se suspendieron las clases presenciales, de manera que diversos escolares tuvieron dificultades para continuar el curso al no disponer de los pertinentes medios tecnológicos. El cierre de las escuelas conllevó además que los alumnos becados con comedor perdieran inicialmente este beneficio (A3, D1-D8, I1). Otros efectos destacados durante este periodo han sido el cierre del Centro de Día de Mayores y del Programa del Mayor, la paralización de las actividades formativas y de ocio dirigidas a la población joven, así como la cancelación de las actividades destinadas a personas con diversidad funcional (A6, A7, I9, I10).

\subsubsection{Colectivos vulnerables y brecha social}

La brecha económica derivada de la crisis, y la intensificación por el confinamiento establecido, han evidenciado en el municipio una mayor vulnerabilidad en ciertos colectivos poblacionales, entre los que destacan las personas mayores y dependientes, las mujeres víctimas de violencia de género, los menores sin los medios necesarios para continuar el curso académico a distancia, las personas con diversidad funcional, así como los ciudadanos que han perdido sus empleos (A6, C1-C4, D1-D8, I9, I11). Además, se ha detectado la aparición de nuevos colectivos vulnerables, principalmente referidos a los habitantes dedicados a la economía informal o actividades no declaradas, como las relacionadas con el cuidado de mayores o la limpieza doméstica. El confinamiento supuso la paralización de estas tareas, por lo que las personas implicadas perdieron sus ingresos económicos y no pudieron acceder a ninguna prestación por desempleo (A4, B5, C1-C4). Asimismo, el informe técnico elaborado por el Área de Igualdad (I11) señala que en esta etapa se ha registrado un aumento de los casos de violencia de género, con un incremento de las denuncias presentadas y de las llamadas telefónicas recibidas. También es relevante el impacto psicológico que supone una pandemia de esta virulencia.

Las desigualdades en el acceso y uso de las nuevas tecnologías en la sociedad han incidido en los diferentes colectivos poblacionales, tanto a nivel personal como profesional. En este sentido, los grupos sociales más afectados son las personas mayores y los habitantes con menores recursos económicos y/o con un bajo nivel sociocultural (A4, A5, A6, C1-C3).

\subsubsection{Medidas sociales}

El Área de Servicios Sociales ha implementado diversas medidas dirigidas a mitigar los impactos de la crisis. Desde el estado de alarma se han registrado numerosas solicitudes de ayuda por parte de personas necesitadas, por lo que el Ayuntamiento destinó partidas económicas específicas a colectivos vulnerables (A4, A6). La cantidad de ayudas de emergencia social concedidas en el año 2020 se ha incrementado un $33 \%$ respecto a la anterior anualidad. De este modo, en 2019 se concedieron prestaciones por un valor de 191.386 euros, y en 2020 ascendieron a 254.231 euros. Estas subvenciones están destinadas a sufragar gastos de comida, luz, alquiler, transporte, agua o préstamos, de las que se han beneficiado unas 800 personas (Ayuntamiento de Riba-roja de Túria, 2021a).

Según la información ofrecida en la página web municipal (Ayuntamiento de Riba-roja de Túria, 2021a), el Ayuntamiento implantó, a finales del mes de marzo de 2020, un servicio de Apoyo Psicológico COVID-19 en coordinación con el centro de salud, con el objeto de atender telefónicamente a personas que mostraban dificultades para afrontar la nueva situación. Además, se habilitó un teléfono municipal de Asesoramiento Legal, y a principios del mes de abril entró en funcionamiento un "Call Center", en el que se ha atendido y asesorado a la ciudadanía sobre diferentes temáticas desde las distintas áreas municipales.

Durante el estado de alarma se atendieron dos centenares de personas en el catering social de Riba-roja de Túria, el doble que en la anualidad precedente. Del mismo modo, en este periodo se 
proporcionó alojamiento a diversas familias que habían perdido su vivienda, y se facilitó la conexión a Internet a personas vulnerables (A6, I9). Asimismo, al Ayuntamiento ofreció atención específica a aquellos ciudadanos que mostraban dificultades para la realización de trámites administrativos telemáticos (A5, I12).

En relación al colectivo de mayores, el Área de Servicios Sociales repartió material sanitario en centros de día y residencias durante el confinamiento, y entregó en préstamo una quincena de tabletas con conexión a Internet. Después del estado de alarma, el Ayuntamiento ha retomado las actividades dirigidas a este colectivo con las pertinentes adaptaciones a la nueva normalidad, y ha reactivado el programa de atención a personas con diversidad funcional (A6, I9).

La coordinación del Área de Servicios Sociales y el Área de Educación ha sido fundamental para cubrir las necesidades de los menores. Durante el confinamiento se repartieron dispositivos con Internet para seguir las clases a distancia, y se estableció un servicio de entrega y recogida de deberes a domicilio (D1-D8, I1). Durante los meses estivales, el Ayuntamiento garantizó el comedor a la totalidad de menores en situación de vulnerabilidad (I9).

Está prevista la creación de una Agencia Municipal para el acceso a la Vivienda Social con la finalidad de ayudar a diversos colectivos. Asimismo, se prevé la formación de una bolsa de viviendas vacías (Ayuntamiento de Riba-roja de Túria, 2021a).

Desde el Área de Mujer e Igualdad se han realizado acciones relacionadas con la violencia de género. Durante el estado de alarma se atendió telefónicamente a diversas mujeres víctimas de maltrato, y se proporcionó información sobre aplicaciones dirigidas a alertar sobre este tipo de situaciones. De la misma manera, se expusieron carteles con información y números telefónicos de atención a la violencia de género en diferentes lugares del municipio, y se informó en redes sociales sobre el agravamiento de estas situaciones (A6, I11).

\subsection{Crisis económica}

El estado de alarma, la paralización de las actividades económicas no esenciales, y el confinamiento de la población, conllevaron un impacto destacado en los niveles de actividad y empleo del municipio, así como una sensación de incertidumbre en el sector empresarial (B1-B5, C1-C3, I2). La pandemia ha incidido fundamentalmente en las actividades no consideradas esenciales y que dependen de la presencialidad. Además, el teletrabajo ha permitido a determinadas empresas mantener su actividad (A2, A4).

\subsubsection{Evolución de las actividades económicas}

En referencia al sector agrario, los representantes municipales del Área de Agricultura, de AVA Consell Agrari y de la Comunidad de regantes, consideran que la crisis no ha tenido un impacto económico relevante en esta actividad. Estos agentes afirman que el COVID-19 ha generado beneficios entre los agricultores profesionales, principalmente los dedicados a la citricultura. Durante el confinamiento se registró un incremento de los precios de determinados cultivos, sobre todo la naranja, debido a la implementación de restricciones en los mercados exteriores y a un mayor consumo en el mercado de proximidad. No obstante, la pandemia ha afectado a la agricultura familiar y a los agricultores dedicados a los huertos de autoconsumo (A2, E1).

En las áreas industriales, la incidencia de la crisis ha dependido fundamentalmente de la actividad considerada (A4, B1-B2, B5, C1-C3). Durante las primeras semanas de confinamiento, el COVID-19 impactó de manera destacada en el sector industrial, con descensos generales en la facturación de las empresas. Sin embargo, posteriormente se ha producido una progresiva recuperación económica, principalmente en ámbitos esenciales, como la alimentación y el transporte, así como en la logística, principal actividad de Riba-roja de Túria. En consecuencia, el impacto de la crisis en las áreas industriales no ha sido tan acusado como el acontecido en otros ámbitos territoriales valencianos. Asimismo, según las encuestas realizadas por diversas asociaciones empresariales de la localidad, la crisis ha tenido una repercusión menor que la que prevista inicialmente. No obstante, en algunas actividades como la automoción, la incidencia de la pandemia ha sido más destacada y prolongada. En la actualidad, las previsiones entre los empresarios son en general optimistas (B1-B2). 
En el sector de los servicios, el comercio local ha sido una de las actividades más perjudicadas por el impacto de la crisis, tal y como han señalado los representantes de la Concejalía de Comercio y la Asociación de comercio local en sus respectivas entrevistas (A2, B3). No obstante, en estas reuniones se indicó que la incidencia de la pandemia ha dependido de la tipología del establecimiento. Los comercios de productos esenciales, como los de alimentación o droguería, no tuvieron que paralizar su actividad, por lo que su evolución ha sido favorable y positiva. Otros ámbitos como los de la restauración, la hostelería o el textil, han sufrido un mayor impacto, con una reducción de su facturación. En las fases de desescalada la totalidad de comercios reiniciaron su actividad. En este periodo los habitantes no podían desplazarse a realizar compras a otros municipios, por lo que aumentaron las ventas en los establecimientos locales, y se constató una mayor valoración y sensibilización social hacia el pequeño comercio. La crisis ha evidenciado la necesidad de potenciar la digitalización y adaptación a las nuevas tecnologías de los comercios locales, ya que los establecimientos con venta online han amortiguado mejor los efectos de la pandemia (A2, B3).

La hostelería continúa siendo actualmente uno de los ámbitos más damnificados. De hecho, como consecuencia del impacto de la pandemia en el sector, se ha constituido recientemente una asociación de hostelería en el municipio (B4). En relación al turismo, las limitaciones de movilidad también han afectado a su habitual dinamismo, con una disminución significativa del número de visitantes y turistas $(\mathrm{A} 9, \mathrm{I} 7)$.

\subsubsection{Mercado laboral: desempleo y contratación}

La crisis del COVID-19 ha repercutido de manera considerable en el mercado de trabajo. La Figura 3 muestra la evolución mensual del número de demandantes de empleo en la localidad en los años 2019 y 2020. Como se observa, durante el estado de alarma se produce un incremento relevante del número de desempleados, de manera que las cifras analizadas son superiores a las contabilizadas en las mismas mensualidades del año 2019. El desempleo ha tenido una especial virulencia en las personas con menores cualificaciones profesionales y académicas (I2). A partir de junio, y durante los meses posteriores, se observa un progresivo descenso del número de parados, merced a la recuperación económica desarrollada tras el confinamiento y a la eficacia de las medidas implantadas por los actores del territorio. En este periodo las cifras se aproximan a las registradas en la anualidad precedente y las previsiones son en general positivas (A4, B5). Las personas sujetas a ERTE no se contemplan como demandantes de empleo, por lo que es conveniente analizar en el futuro su repercusión en la estructura laboral local.

Figura 3. Evolución mensual del número de desempleados en Riba-roja de Túria durante los años 2019 y 2020

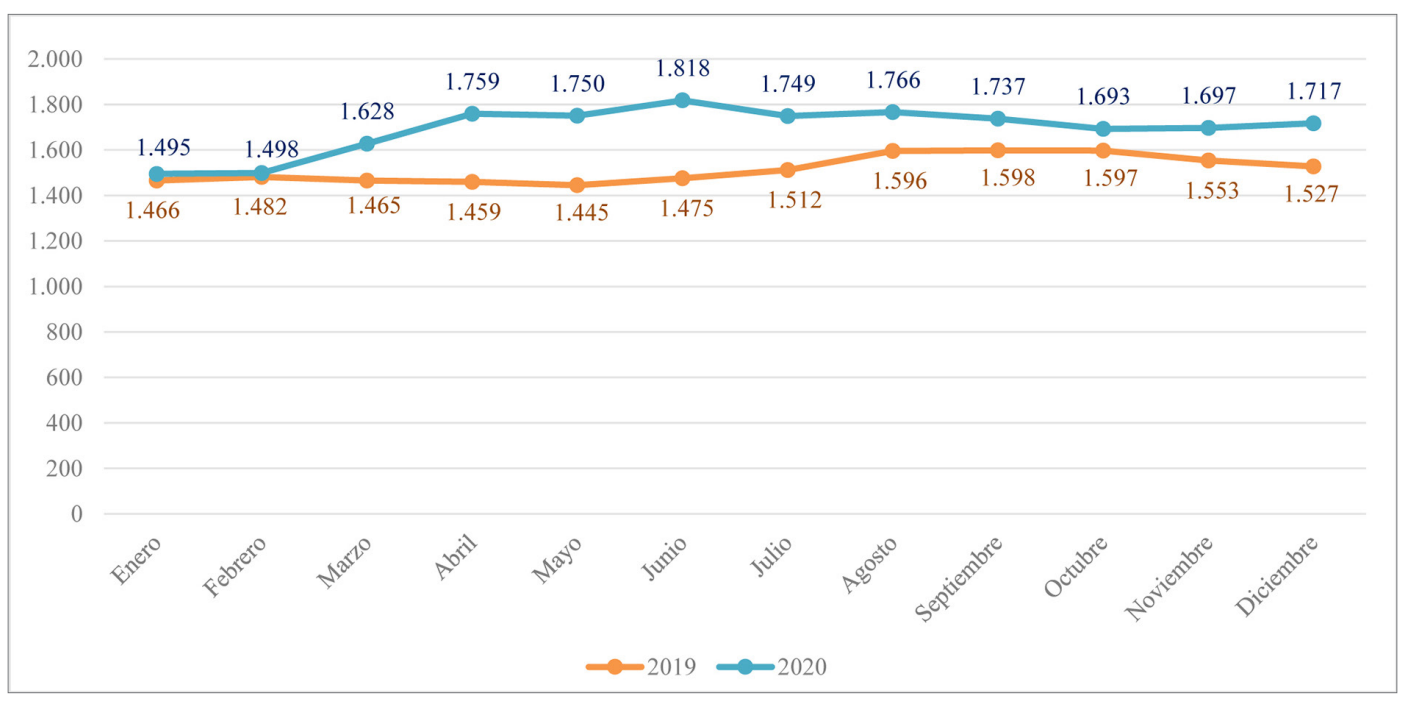

Fuente: LABORA, 2021b. Elaboración propia

En referencia a la contratación, la Figura 4 recoge la evolución mensual del número de contratos efectuados en Riba-roja de Túria durante los años 2019 y 2020. En el periodo de confinamiento se constata 
un acusado descenso de la contratación como consecuencia de la paralización de diversas actividades y la incertidumbre. De hecho, en el segundo trimestre del año, las cifras son muy inferiores a las contabilizadas en la anualidad precedente. A partir de julio mejora la situación económica y se produce un elevado incremento en la contratación. Las cifras del tercer y cuarto trimestre son similares a las de 2019, incluso en diciembre las contrataciones son superiores a las efectuadas en este mismo mes durante el pasado año.

Figura 4. Evolución mensual de la contratación en Riba-roja de Túria durante los años 2019 y 2020

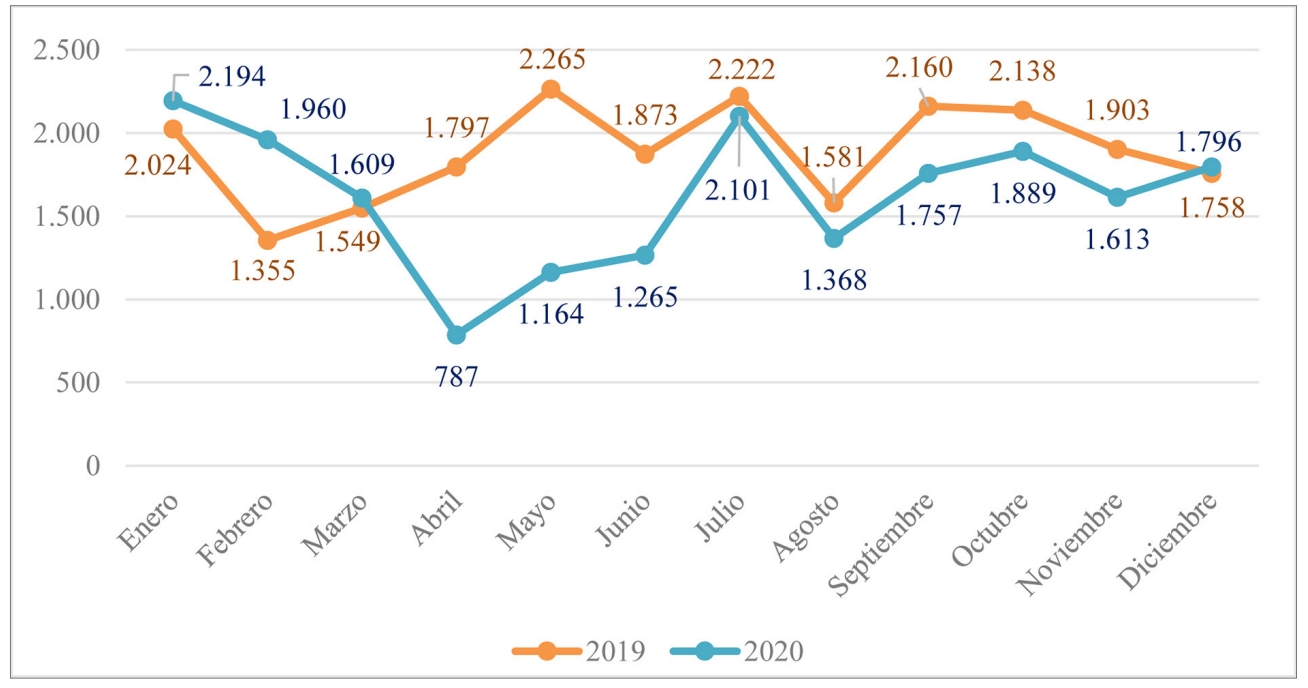

Fuente: LABORA, 2021a. Elaboración propia

\subsubsection{Expedientes de Regulación Temporal de Empleo}

Los Expedientes de Regulación Temporal de Empleo (ERTE) han sido utilizados por numerosas empresas. Las Figuras 5 y 6 muestran la evolución del número de ERTE y de trabajadores afectados entre los años 2001 y 2020 en Riba-roja de Túria. La incidencia del COVID-19 ha provocado un aumento extraordinario de las estadísticas analizadas. De esta manera, en la localidad se han registrado 347 ERTE y 4.245 trabajadores perjudicados en el año 2020, mientras que en las anualidades anteriores los máximos se produjeron durante la crisis económica inmobiliaria, con cifras muy inferiores a las actuales. Según su causa, el 78,4\% de los ERTE y el 56,7\% de los empleados afectados de 2020 son de fuerza mayor, de modo que se relacionan directamente con el impacto de la pandemia.

Figura 5. Evolución del número de ERTE en Riba-roja de Túria entre los años 2001 y 2020

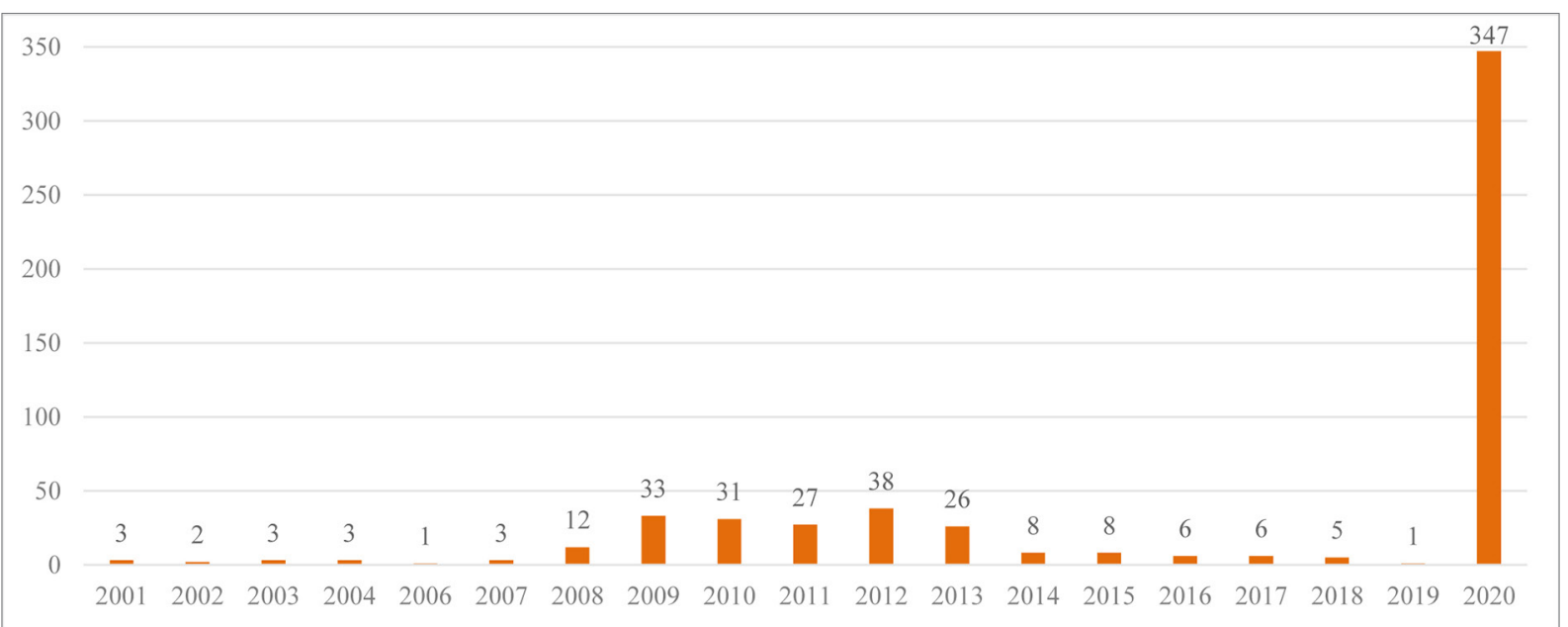

* Los datos de 2020 comprenden hasta el 30 de junio

Fuente: Información proporcionada por LABORA. Elaboración propia 
Figura 6. Evolución del número de trabajadores afectados por ERTE en Riba-roja de Túria entre los años 2001 y 2020

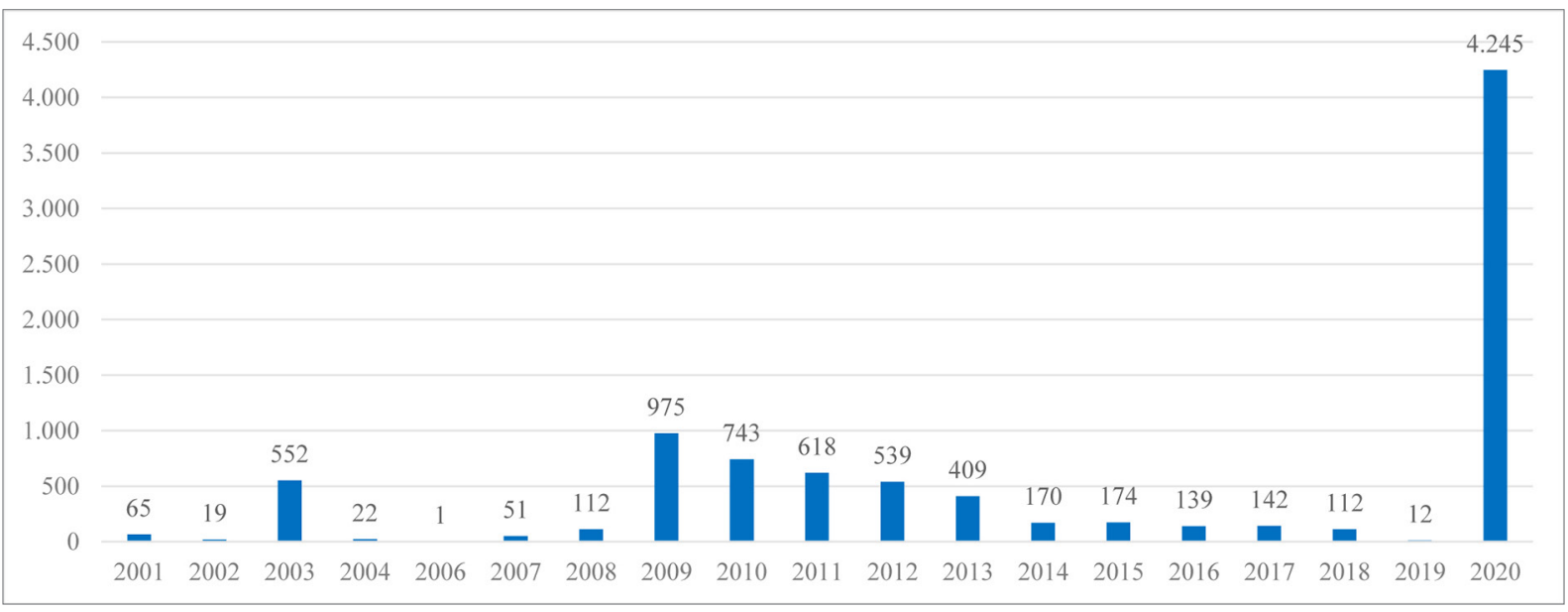

* Los datos de 2020 comprenden hasta el 30 de junio

Fuente: Información proporcionada por LABORA. Elaboración propia

\subsubsection{Medidas económicas}

La Administración pública local ha desarrollado diferentes acciones destinadas a mitigar o resolver las dificultades surgidas en el ámbito económico y laboral. En este sentido, se realizó una significativa redistribución del presupuesto municipal, y se priorizaron partidas de mayor urgencia y necesidad, con modificaciones que ascendieron a 3 millones de euros. Destaca la puesta en marcha de una partida de 670.000 euros destinada a la concesión de ayudas directas municipales dirigidas a autónomos, comercios, profesionales y microempresas perjudicadas por la incidencia de la pandemia (A4). Además, durante el estado de alarma, el Ayuntamiento paralizó varias tasas y aplazó el pago de diversos impuestos.

En el mes de abril de 2020, el equipo de gobierno creó una comisión de seguimiento económico del COVID-19. Su función es la implementación de actuaciones para afrontar incidencias socioeconómicas y laborales vinculadas con la pandemia. Además, constituyó un área municipal específica de Economía y Hacienda, y habilitó un servicio telefónico de asesoramiento laboral. En el mes de mayo, el pleno aprobó la elaboración de un plan municipal con la finalidad de potenciar la participación de las pequeñas y medianas empresas (pymes) y los profesionales o autónomos de Riba-roja de Túria en la licitación de los contratos públicos (Ayuntamiento de Riba-roja de Túria, 2021a).

El "Plan RibActiva" es un programa municipal destinado al fomento de la economía y el empleo en Riba-roja de Túria (A4). Comprende las siguientes líneas de ayudas económicas directas: "RibActiva Impulsa't", enfocada a autónomos y microempresas que tuvieron que cerrar sus negocios como consecuencia del estado de alarma; "RibActiva Consolida't", dirigida a establecimientos comerciales minoristas y otros pequeños negocios que redujeron su facturación en marzo y abril; "RibActiva Emprén", destinada a autónomos y profesionales del comercio minorista que iniciaron su actividad entre enero y octubre de 2020; y "RibActiva Col-labora", para autónomos colaboradores de comercios minoristas que presentan servicios al consumidor final. La cuantía de las ayudas por beneficiario oscila entre los 500 y 2.000 euros.

Finalmente, los entrevistados del Área de Comercio (A2), destacaron el desarrollo de las siguientes campañas municipales de incentivos al consumo en el comercio local: "Col.le Xec", mediante la concesión de ayudas económicas destinadas a la adquisición de material y accesorios escolares en comercios minoristas de Riba-roja de Túria; "Cheque Bebé +", que otorga incentivos a las familias con hijos nacidos entre el 14 y 30 de junio de 2020, destinados a la compra de enseres para el cuidado del menor en negocios locales; y "Rasca\&Guanya", donde se reparten rascas con premios económicos entre los clientes que adquieran productos en los establecimientos adheridos a esta campaña, para su posterior canjeo en otros comercios locales participantes.

\subsection{La reacción institucional: el Ayuntamiento}

La Administración pública local ha implementado diferentes medidas con el objeto de mitigar y resolver los efectos de la pandemia. El Ayuntamiento constituyó el 12 de marzo de 2020 un Comité 
de Seguimiento del COVID-19, integrado por las autoridades municipales y sanitarias, así como por el personal técnico concernido en la materia. Sus propósitos son gestionar de manera eficaz esta situación extraordinaria, y establecer actuaciones adaptadas a las indicaciones que dictaminan las autoridades competentes. De la misma manera, en el inicio de la crisis, el Consistorio puso en marcha el programa "El teu Ajuntament amb tu", en el que se enmarcan las numerosas actuaciones adoptadas por el Ayuntamiento complementarias a las establecidas por otras administraciones (Ayuntamiento de Riba-roja de Túria, 2021a). Las diferentes áreas municipales han implantado planes de contingencia y proyectos para mejorar la actual situación, y se han efectuado obras en los edificios públicos para su adaptación a los protocolos establecidos (Al, I8).

El Ayuntamiento ha ejecutado planes y programas de carácter transversal. Destaca el "Plan de Choque Desinfecta", destinado a la desinfección integral del municipio (A8). Este plan comprende la limpieza de espacios públicos, principalmente los entornos urbanos con mayores concentraciones de población, las calles y plazas, los edificios y vehículos municipales, así como el transporte público. Estas actuaciones se han complementado con la colaboración voluntaria de tractoristas y agricultores de la localidad, que han contribuido en las desinfecciones de viales (E1). Del mismo modo, la Policía Local se ha adaptado a las dinámicas derivadas de la pandemia. Se ha aumentado la presencia y vigilancia en determinados espacios, con el objeto de controlar el cumplimiento de las restricciones y normativas establecidas (A5, I14). La función de los medios de comunicación locales, como la radio o televisión municipales, ha sido esencial para la transmisión de contenidos a la población durante el confinamiento. Las redes sociales han adquirido una relevante importancia como medio de información actualizado y de participación ciudadana (A9, I5).

Según recoge la página web del Consistorio (Ayuntamiento de Riba-roja de Túria, 2021a), el presupuesto municipal del año 2021 se sitúa en 32 millones de euros, de los que 1,4 se destinan a actuaciones de carácter transversal dirigidas específicamente a la lucha contra el COVID-19, enfocadas en áreas como Educación, Sanidad, Limpieza o Comercio. Otras partidas destacadas se centran en el fortalecimiento de las políticas sociales para mitigar la situación de las personas de mayor vulnerabilidad, así como en el fomento económico, el empleo y la formación. Además, se ha aprobado una congelación de los impuestos y las tasas municipales.

\subsection{La reacción de la sociedad local}

Las limitaciones y restricciones de movilidad establecidas, principalmente durante el periodo de confinamiento, han conllevado en la actualidad una mayor concienciación medioambiental y sensibilidad por la población hacia los espacios abiertos y los entornos naturales próximos, entre los que destaca el Parque Natural del Túria (A2, E2, I4). Numerosos habitantes han desarrollado hábitos y prácticas saludables, de manera que, en la desescalada y los meses posteriores, se ha detectado un aumento del uso de los carriles bici municipales, de los paseos y senderos peatonales o senderistas, así como de la realización de actividades deportivas y otras prácticas al aire libre (A8, I3). La ciudadanía valora en mayor medida el estado y el mantenimiento del viario y mobiliario urbano, de las áreas verdes municipales, y de las instalaciones y los espacios de uso público (A1). Asimismo, se ha detectado un descenso del número de usuarios del transporte público a favor del vehículo particular y carril bici. Según la información proporcionada por el Ayuntamiento (I6), en septiembre de 2020 se ha registrado una reducción de 5.530 viajeros de los autobuses municipales en relación a la misma mensualidad del año anterior. La principal causa que se contempla es el temor al contagio, ya que los usuarios en ocasiones optan por utilizar vehículos particulares y otros medios de transporte individual.

El municipio ha registrado, tras el estado de alarma, un aumento poblacional en áreas de urbanizaciones y segundas residencias, así como en ámbitos rurales, núcleos diseminados y casas de campo (Al, A8, A11-13, I13). Este incremento es debido a los desplazamientos de habitantes provenientes de áreas urbanas a estos espacios de menor aglomeración de la localidad, dada la cercanía de la ciudad de Valencia y su área metropolitana a Riba-roja de Túria. Estos sectores del término, que anteriormente se utilizaban de manera discontinua en periodos vacacionales o fines de semana, en la actualidad se han convertido en ámbitos a los que se han trasladado numerosos habitantes para residir en búsqueda de espacios al aire libre, una mayor proximidad a áreas naturales, y una mejora de la calidad de vida (A2, A8). Además, se advierte un interés promocional por nuevas zonas residenciales y la construcción de unifamiliares (I8). 
Los agentes sociales han emprendido acciones dirigidas a paliar el impacto de la crisis. Las asociaciones y entidades locales han focalizado sus esfuerzos en reducir la incidencia de la pandemia y ayudar a la sociedad (A9). La crisis ha hecho aflorar la solidaridad de los habitantes y colectivos municipales. De este modo, durante el estado de alarma, numerosos vecinos y empresas elaboraron y repartieron material de protección y ayudaron a los colectivos poblacionales de mayor vulnerabilidad (A6). También se realizaron donaciones de alimentos por parte de los comercios locales (A2, B3), se efectuaron recaudaciones por los clubes deportivos (A10), y se ofreció alojamiento a personas en riesgo de exclusión (19). En definitiva, se constata el surgimiento de multitud de iniciativas voluntarias en la sociedad, destinadas a apoyar a los habitantes más vulnerables, a la creación de redes de colaboración, y a mitigar las desigualdades existentes.

Figura 7. Procesos y dinámicas derivadas del COVID-19 en Riba-roja de Túria

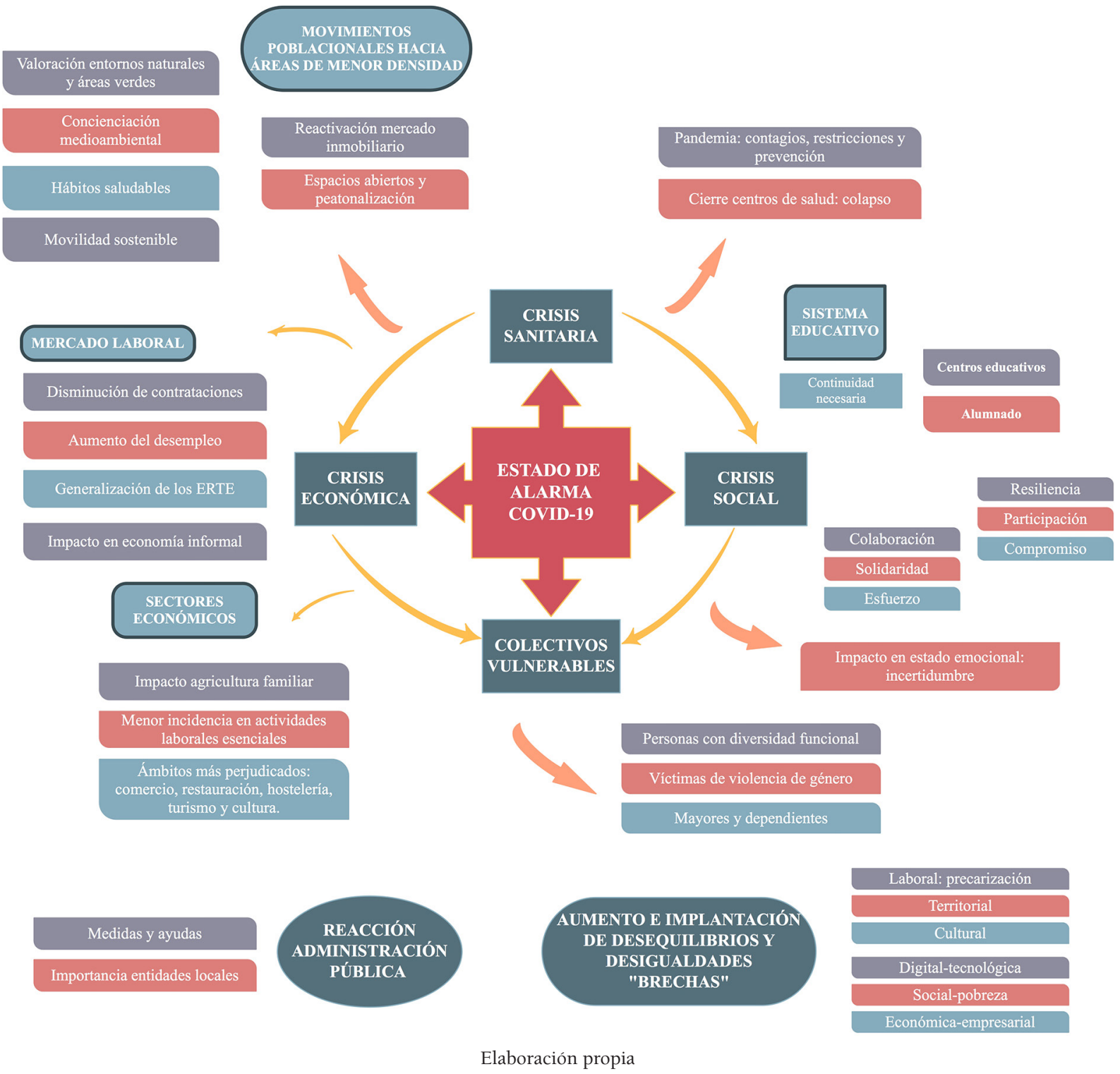

\section{Discusión de resultados}

El impacto de la pandemia y la efectividad de las acciones implementadas varían en función de las particularidades de cada ámbito territorial. Sin embargo, la magnitud del COVID-19 es global, por lo que es posible identificar dinámicas comunes en las áreas urbanas de las coronas metropolitanas a partir de su estudio en Riba-roja de Túria, y de este modo, plantear estrategias conjuntas dirigidas a conseguir modelos territoriales más resilientes y equilibrados. 
La crisis ha agravado y evidenciado diversas problemáticas y debilidades de los modelos de desarrollo territorial y de los sistemas sanitario, económico y social de las ciudades. El actual escenario motiva a reflexionar sobre las formas de vida de la población y a plantear estrategias dirigidas a responder a la realidad del COVID-19, con objeto de conseguir espacios urbanos más resilientes, inclusivos, sostenibles y habitables. En este sentido, la crisis representa una oportunidad para analizar los vínculos entre la planificación urbana, el espacio público y el bienestar (Giglia, 2020), y debe abordarse desde la coordinación de múltiples disciplinas y con la participación de las diferentes administraciones públicas.

La pandemia ha impactado en la percepción y usos de los espacios públicos. Los habitantes muestran una mayor sensibilidad hacia los lugares peatonales y abiertos, el estado del viario y mobiliario urbano, y las instalaciones públicas. En consecuencia, la planificación urbana se focaliza actualmente en la mejora de la calidad formal y salubridad de estos lugares, con objeto de conformar ciudades sostenibles, saludables e inclusivas. De la misma manera, el distanciamiento social comporta la necesidad de ampliar los espacios y senderos peatonales o ciclistas, y dotarlos de los elementos de accesibilidad necesarios para su uso por la totalidad de los ciudadanos. De hecho, en la localidad de estudio se han realizado en los últimos meses diversas actuaciones municipales centradas en el aumento de lugares lúdicos al aire libre y de los espacios peatonales.

Asimismo, la crisis conlleva un aumento de los desplazamientos de habitantes provenientes de espacios urbanos hacia áreas de urbanizaciones, diseminados y ámbitos rurales. Se producen movimientos desde las grandes ciudades y áreas metropolitanas a municipios de menor densidad poblacional en búsqueda de lugares al aire libre, espacios naturales y mayor bienestar. Los estudios de Llorente-Adán y Ruíz-Tricio (2020) y Molina, de Pablo, Milán y Caparrós (2020) señalan que la pandemia y el confinamiento han conllevado una mayor apreciación y valoración de la calidad de vida que ofrecen los pequeños núcleos de población y las áreas rurales. Este proceso se constata en el municipio de Riba-roja de Túria, con un incremento poblacional en urbanizaciones, áreas de segundas residencias y núcleos diseminados.

La crisis incide en el tejido productivo y las economías locales. Durante el confinamiento, un considerable número de empresas redujeron su actividad o cesaron de manera definitiva, con la consecuente reducción del empleo y la contracción de la economía. La paralización de las actividades no esenciales generó una sensación de incertidumbre entre las empresas, con un aumento del desempleo y los ERTE, así como un descenso de la contratación, tal y como se ha verificado en la localidad de estudio. El impacto más destacado se detecta en las actividades no esenciales y dependientes de la presencialidad, con una significativa virulencia en el sector laboral más precario y en la economía informal. Además, afectó con más intensidad a sectores con mayor cantidad de pequeñas y medidas empresas y trabajadores autónomos (Garamendi, 2020).

Las administraciones han impulsado diferentes actuaciones dirigidas a las mejoras del mercado laboral. Es necesario activar la economía local y establecer estrategias a medio y largo plazo. Algunas posibles acciones se focalizan en el impulso a las pymes y a sectores como el pequeño comercio, así como en la adopción de herramientas de protección social para los habitantes dedicados a la economía informal. Además, es esencial fomentar un modelo de producción sostenible y responsable, y alcanzar economías diversificadas y resilientes.

En referencia al sector agrario, las políticas públicas anti-COVID en España favorecieron la agroindustria en detrimento de la agricultura familiar (Gascón, 2020). Las principales restricciones que afectaron a este ámbito durante el confinamiento fueron el cierre de los mercados no sedentarios de venta directa, la prohibición de los desplazamientos a los huertos de autoconsumo, y la pérdida de dos de sus vías de comercialización: los comedores escolares y los servicios HORECA (Hoteles, Restaurantes y Cafeterías). En el análisis del caso de estudio se confirma la generación de beneficios entre los agricultores profesionales durante el confinamiento, mientras que la agricultura de autoconsumo registró pérdidas en este periodo.

En el sector industrial, el mayor impacto económico ocurrió en las primeras semanas desde la declaración del estado de alarma. La incidencia de la pandemia ha dependido en gran medida de la actividad industrial considerada. En sectores esenciales como la alimentación, el transporte o la logística, el impacto es menor, tal y como se ha refrendado en Riba-roja de Túria. Sin embargo, en otros ámbitos como la automoción, los efectos han sido más destacados y prolongados. Actualmente las previsiones son positivas.

El comercio local es uno de los sectores más perjudicados, aunque se constatan diferencias en función de la tipología del establecimiento y el periodo considerado. Durante el confinamiento, los comercios 
esenciales registraron un aumento de sus ingresos, mientras que el resto de ámbitos disminuyeron su facturación. En la desescalada se produce un aumento generalizado de las ventas en el comercio local (García, 2020). En la actualidad se detecta una mayor concienciación hacia el pequeño comercio. La hostelería y el turismo también han sufrido un impacto significativo. Estas dinámicas se han identificado en la localidad de estudio. Diversos estudios afirman que los sectores económicos afectados en mayor medida por la crisis son el comercio, la restauración, la hostelería, el turismo o la cultura (González, Armesto, Sánchez y Lago, 2020; López y Durán, 2020).

La crisis supone un incremento de la pobreza y de las desigualdades existentes, y, por tanto, del riesgo de exclusión. Se ha producido un aumento de la brecha social y se evidencia una mayor vulnerabilidad en diversos colectivos poblacionales, como los mayores, desempleados, dependientes, personas sin hogar, mujeres víctimas de violencia de género, migrantes, menores sin acceso a Internet, personas con diversidad funcional, y habitantes dedicados a la economía informal. De hecho, la pandemia en Riba-roja de Túria ha incidido con mayor virulencia en los mencionados colectivos. Según el informe anual de desigualdad que publica Oxfam Intermón (2020), el COVID conlleva un aumento de la pobreza severa en España.

La población que reside en áreas de mayor vulnerabilidad tiene dificultades para acceder a los bienes y servicios públicos esenciales. Por ello, es conveniente que las administraciones competentes inviertan en la mejora de los espacios marginales y faciliten la cobertura de las necesidades básicas a la totalidad de la ciudadanía durante la crisis, en aspectos como el abastecimiento de agua, el alojamiento o el suministro eléctrico. Asimismo, la pandemia visibiliza los problemas de habitabilidad que padecen numerosas personas. El hacinamiento en hogares de escasa calidad, la infravivienda o el tamaño de las propias casas, complican el distanciamiento social e incrementan el riesgo de contagio. La inestabilidad residencial, las dificultades para adquirir una vivienda o los precios abusivos del mercado empeoran la situación. En consecuencia, sería interesante el diseño de hogares con espacios abiertos, y establecer mecanismos que faciliten el acceso a viviendas públicas y asequibles a la población más vulnerable.

Durante el confinamiento y el periodo posterior, la población ha desarrollado hábitos saludables, con un aumento del uso de los carriles bici, de los senderos peatonales, y de la realización de prácticas al aire libre y deportivas. Además, la pandemia conlleva un cambio de los hábitos de movilidad, con un descenso del número de usuarios de transporte público a favor del vehículo privado o particular. El artículo de Medina (2020) analiza la evolución de viajeros de transporte público durante el año 2020 en diversas ciudades españolas, en las que se constata un acusado descenso respecto a la anterior anualidad. Las principales causas que se contemplan son el temor al contagio, la implantación del teletrabajo, la educación a distancia, las pérdidas de empleo, o el cierre ocasional de los establecimientos de ocio. Estas dinámicas se verifican en la localidad de estudio. Por ello, es esencial plantear la futura movilidad sostenible de las áreas urbanas, mediante el impulso de los recorridos a pie y en bicicleta, así como el uso del transporte público. Los sistemas de transporte sostenibles se configuran como elementos fundamentales en los actuales espacios urbanos.

Las limitaciones de movilidad establecidas durante el estado de la alarma conllevaron una mayor sensibilización y preocupación social hacia el medioambiente y la sostenibilidad. La ciudadanía valora en mayor medida los entornos naturales y los espacios abiertos. La investigación de Venter et al. (2020) constata un aumento del número de caminantes, senderistas y ciclistas en los espacios verdes durante la crisis, así como de la actividad peatonal en los parques urbanos y áreas protegidas. El estudio de Grima et al. (2020) señala que las visitas a las áreas naturales y espacios verdes urbanos y periurbanos aumentan como consecuencia de las restricciones derivadas de la pandemia. En el caso de Riba-roja se observa un mayor disfrute y valoración hacia el Parque Natural del Túria por parte de los habitantes. En este sentido, el trabajo de Venter, Barton, Gundersen, Figari y Nowell (2020) destaca el valor de la naturaleza urbana como una infraestructura de resiliencia durante la crisis. Por ello, es recomendable el aumento de las áreas verdes y zonas naturales en las ciudades, ya que aportan beneficios para la salud física y mental de los habitantes, y contribuyen a la preservación de la biodiversidad.

La pandemia incide en la dinámica habitual de los centros de enseñanza. En el confinamiento se produce el cierre obligatorio de los colegios y otras entidades educativas, que tuvieron que realizar significativos esfuerzos para adaptarse a la situación y coordinarse con las familias y la Administración. La adaptación realizada por el profesorado y el personal de los centros educativos durante este periodo se analiza en diversos estudios, como el de Díez y Gajardo (2020), el de Aznar (2020) o el de Joshi, Vinay y Bhaskar (2021). En las entrevistas mantenidas con los directores de los centros educativos de Riba-roja de 
Túria se constataron estos procesos. En el confinamiento se detectaron problemáticas relacionadas con la brecha digital y formativa. Diversos alumnos, principalmente en las familias de menor capital sociocultural y socioeconómico, mostraron dificultades para continuar las clases de modo virtual al no disponer de recursos digitales, herramientas culturales, o condiciones materiales, personales o emocionales propicias (Cabrera, 2020; Cabrera, Pérez y Santana, 2020; García, Rivero y Guerra, 2020). En el presente curso se ha producido la vuelta a la presencialidad, lo que supone un esfuerzo conjunto para el cumplimiento de las restricciones establecidas.

La crisis requiere un mayor uso de las herramientas tecnológicas, tanto en el ámbito personal como profesional. Se consolidan elementos como el teletrabajo, el comercio electrónico, la educación online, la teleasistencia, o las relaciones sociales a distancia. De este modo, la digitalización es una aliada contra la pandemia y ofrece una amplia diversidad de oportunidades, pero también genera desequilibrios (Colom, 2020). En este sentido, el COVID-19 incrementa las desigualdades socioeconómicas, y acentúa la brecha digital, entendida no únicamente como el acceso y uso desigual a las nuevas tecnologías, sino también como la exclusión digital de ciertos colectivos. Los grupos más afectados son los mayores y los habitantes con mínimos recursos económicos y/o con un bajo nivel sociocultural. Estos procesos se corroboran en la localidad de análisis. Ante la diversidad de brechas generadas por el distinto uso de las nuevas tecnologías, las autoridades competentes deben potenciar la cobertura y accesibilidad a las herramientas tecnológicas y a Internet, así como fomentar la alfabetización, la formación y la inclusión digitales.

De la misma manera, la pandemia acelera la implantación de nuevas tecnologías y el proceso de digitalización en el ámbito empresarial, debido a la necesidad de flexibilización laboral y el auge del teletrabajo (Oubiña, 2020). El empleo a distancia permitió a determinadas empresas mantener su actividad. Diversos estudios señalan que las entidades que han implementado el teletrabajo o el comercio online han amortiguado mejor los efectos de la pandemia (Izquierdo y Vicente, 2020). Sin embargo, aquellas entidades que no disponen de las infraestructuras necesarias se han visto notablemente perjudicadas. Este proceso es patente en el ámbito del comercio electrónico en Riba-roja de Túria, donde el uso de medios digitales supone un elemento diferenciador para afrontar la crisis.

Las administraciones públicas implementan medidas y ayudas dirigidas a mitigar y resolver las adversidades, desigualdades y problemáticas derivadas de la pandemia. En concreto, las entidades locales realizan significativos esfuerzos en el desarrollo de acciones para mejorar la actual coyuntura, lo que ha facilitado la potenciación de sinergias y del trabajo colaborativo. Las medidas implementadas por el Ayuntamiento de Riba-roja de Túria han sido esenciales para mitigar los impactos derivados de la pandemia. El análisis efectuado por Analistas Financieros Internacionales (2020), especifica iniciativas desarrolladas por diferentes entidades locales para paliar los efectos de la crisis sanitaria en materia administrativa, financiera y económica. Del mismo modo, el estudio de Kavan (2021) destaca la eficacia de las medidas implementadas por gobiernos regionales y locales para mitigar el impacto de la crisis en los grupos poblacionales más vulnerables.

Finalmente, es necesario señalar la incidencia de la pandemia en el estado emocional de la población. El estudio de Sandín, Valiente, García-Escalera y Chorot (2020) analiza la incidencia psicológica del confinamiento en una muestra de un millar de habitantes, donde se constatan elevados niveles de impacto emocional relacionados con el temor al contagio, el aumento de la preocupación, el estrés o la ansiedad. No obstante, la crisis también ha hecho aflorar la solidaridad de la sociedad, con el surgimiento de multitud de iniciativas voluntarias, y de apoyo y colaboración entre la ciudadanía (Ponce, 2020). En Riba-roja de Túria se producen numerosas acciones solidarias entre la sociedad, dirigidas a paliar los impactos de la pandemia y las desigualdades. En consecuencia, la crisis ha propiciado el auge de iniciativas ciudadanas de colaboración, y ha reforzado los vínculos comunitarios. Por ello, es fundamental mantener estas redes e interrelaciones sociales, y fomentar la participación ciudadana en la planificación del territorio.

\section{Conclusiones}

La crisis sanitaria del COVID-19 ha supuesto un significativo impacto en la sociedad, y ha incidido de manera destacada en los procesos y dinámicas económicas y sociales de los territorios, principalmente en las áreas urbanas. Las administraciones e instituciones públicas han liderado una respuesta inmediata en el contexto de la crisis, mediante la adopción de medidas para conseguir una rápida recuperación. No obstante, el problema de coordinación y cooperación institucional entre los niveles de administración en 
España representa uno de los obstáculos más significativos en el ámbito de la gobernabilidad. Una situación de emergencia compleja como la del COVID-19 requiere la incorporación de cambios organizativos y relacionales en las formas de gestión y gobernanza tradicionales. Por ello, es necesario conseguir una cooperación y acordar una visión compartida entre la totalidad de niveles y agentes territoriales involucrados, donde los procesos de toma de decisiones deben basarse en un modelo de gobernanza compartida. En este sentido, aspectos como la participación y colaboración entre los diferentes actores adquieren cada vez una mayor importancia.

Las administraciones locales tienen un papel destacado y crítico en la gestión de este tipo de emergencias. En esta investigación se ha analizado y se ha sistematizado el impacto de la pandemia en el municipio valenciano de Riba-roja de Túria. Esta localidad constituye uno de los focos de atracción socioeconómica más significativos del AMV. El Ayuntamiento ha requerido la actualización de su Plan Estratégico, con la finalidad de realizar su correcto seguimiento adaptado a la actual coyuntura.

La crisis ha generado efectos inesperados y problemáticas de diferente tipología en el municipio. En relación al sector sanitario se produce el cierre del centro de salud en el confinamiento. No obstante, dada la transversalidad de este sector, el Área de Sanidad del Ayuntamiento interaccionó en mayor medida con el resto de departamentos municipales durante este periodo. Del mismo modo, la crisis también ha incidido en el ámbito económico. Durante los primeros meses de la pandemia se registró un aumento del desempleo y de los ERTE en el municipio, así como un descenso de las contrataciones. Las actividades más perjudicadas fueron las no esenciales y las vinculadas con la economía informal. Esta crisis económica generó una sensación de incertidumbre generalizada, con un aumento del riesgo de exclusión, una mayor vulnerabilidad y brecha social, así como la generación de cambios rápidos de retorno complicado.

La pandemia ha supuesto además el incremento de las desigualdades en el territorio y un aumento de la brecha digital, donde actualmente se constata una mayor vulnerabilidad en determinados colectivos poblacionales. Estos desequilibrios en el acceso y uso a las nuevas tecnologías en la sociedad inciden en las diferentes actividades y sectores, como el empresarial, el educativo, o el social.

Los agentes territoriales han efectuado acciones para mitigar la incidencia de la pandemia. Los habitantes y las asociaciones locales han emprendido iniciativas de distinta tipología con objeto de ayudar a las personas más perjudicadas y mejorar los efectos de esta situación extraordinaria. Tras el periodo de confinamiento, la ciudadanía otorga un mayor valor a los entornos naturales y los espacios abiertos, por lo que se constata la llegada de nuevos residentes a áreas de menor densidad. Además, existe una mayor concienciación medioambiental.

Ante estas situaciones y adversidades, la Administración pública local ha realizado un significativo esfuerzo dirigido al correcto diseño e implementación de estrategias, mediante la implementación de restricciones y medidas de prevención, así como la adopción de nuevos mecanismos de gobernanza. En el ámbito de la adaptación organizativa y la gestión de la crisis, es necesario destacar la constitución del Comité de Seguimiento del COVID-19 por parte del Ayuntamiento de Riba-roja, con el propósito de gestionar de forma adecuada y eficaz los impactos sobrevenidos. Asimismo, se puso en marcha un programa municipal en el que se integran las medidas implementadas para proteger el interés general de la ciudadanía, y se desarrollaron planes de contingencia desde las diferentes áreas y dependencias. Otros aspectos clave en la gobernanza de la pandemia en el Consistorio fue la adaptación y ampliación de los servicios esenciales a las nuevas necesidades, la reorganización del personal, la estrategia comunicativa al conjunto de la organización y la ciudadanía, así como la colaboración con otros actores sociales. Además, el impulso de la actualización del Plan Estratégico, a través de la realización de entrevistas a actores locales y la participación de los técnicos municipales, ha contribuido a fortalecer la gobernanza territorial en Riba-roja de Túria. En el ámbito económico, el Ayuntamiento proporcionó ayudas directas a empresas y profesionales perjudicados por la crisis. También destacan las campañas destinadas a incentivar el comercio local, así como la redistribución del presupuesto municipal. Finalmente, en el apartado social se observa una mayor atención hacia los colectivos más vulnerables. En definitiva, la actual coyuntura ha puesto de manifiesto la función primordial de las entidades locales como agentes de primera línea en la respuesta a la pandemia.

La incidencia de la crisis difiere en función de las particularidades de cada territorio. No obstante, el carácter global y sistémico de la pandemia ha permitido detectar dinámicas comunes y compartidas con ámbitos de rasgos similares al municipio de estudio. De esta manera, la presente investigación, desarrollada desde el ámbito local, ha posibilitado conocer los procesos acontecidos en las áreas urbanas como 
consecuencia de la crisis. Los resultados obtenidos permiten la identificación y la propuesta de estrategias destinadas a conseguir modelos territoriales más resilientes e inclusivos, y de este modo, hacer frente de manera eficaz a las problemáticas y necesidades derivadas de esta situación. De hecho, se han planteado posibles líneas de acción destinadas a alcanzar modelos urbanos adaptados a la realidad del COVID-19.

En función de la investigación realizada, es posible la definición de futuras líneas de trabajo que son objeto de interés. En primer lugar, sería conveniente la aplicación del mismo estudio en el periodo de un año, con el propósito de valorar la situación de la pandemia en el municipio, y de este modo, identificar los procesos acontecidos. El seguimiento del Plan Estratégico de la localidad facilitará conocer la evolución de las dinámicas detectadas. En segundo lugar, sería necesario analizar en los próximos meses las iniciativas desarrolladas por la Administración de Riba-roja de Túria dirigidas a paliar los efectos de la crisis. De esta manera, será posible compararlas con las estrategias propuestas en este estudio y valorar su grado de eficacia y consecución. Finalmente, sería interesante la implementación del método de trabajo de esta investigación en diferentes ámbitos, principalmente en áreas rurales, con el objetivo de determinar los procesos generales derivados de la pandemia en estos espacios y, en consecuencia, proponer estrategias destinadas a conseguir territorios más resilientes.

\section{Financiación}

Esta investigación ha recibido financiación del Ayuntamiento de Riba-roja de Túria.

\section{Agradecimientos}

Los autores queremos expresar nuestro agradecimiento a las personas entrevistadas en este estudio, por su colaboración e implicación, así como a los redactores de los informes municipales realizados expresamente para esta investigación.

\section{Referencias}

Alburquerque, F. (2020). Reflexiones ante el coronavirus desde los territorios: lineamientos para la discusión de una agenda de reconstrucción económica, social, ambiental e institucional. Revista iberoamericana de gobierno local, (16). Recuperado de https://revista.cigob.net/16-junio-2020/ articulos/reflexiones-ante-el-coronavirus-desde-los-territorios-lineamientos-para-la-discusion-deuna-agenda-de-reconstruccion-economica-social-ambiental-e-institucional/

Analistas Financieros Internacionales. (2020). Medidas de las Entidades Locales para hacer frente a la crisis del COVID-19. Recuperado de https://www.elsectorpublico.es/elsp/noticias/1965224/1662130/0/ medidas-de-las-entidades-locales-para-hacer-frente-a-la-crisis-del-covid-19.html

Andersen, K. G., Rambaut, A., Lipkin, W. I., Holmes, E. C. y Garry, R. F. (2020). The proximal origin of SARS-CoV-2. Nature Medicine, (26), 450-452. http://dx.doi.org/10.1038/s41591-020-0820-9

Ayuntamiento de Riba-roja de Túria. (2021a). Noticias. Recuperado de http://www.ribarroja.es/noticias

Ayuntamiento de Riba-roja de Túria. (2021b). Padrón Municipal del Ayuntamiento de Riba-roja de Túria.

Aznar, F. J. (2020). La educación secundaria en España en medio de la crisis del COVID-19. International Journal of Sociology of Education, Special Issue: COVID-19 Crisis and Socioeducative Inequalities and Strategies to Overcome them, 53-78. http://dx.doi.org/10.17583/rise.2020.5749

Bao, C. B. y Delgado J. M. (2020). Gobernanza con análisis territorial en Emergencia COVID-19. Ciencia Latina Revista Científica Multidisciplinar, 4(2), 801-826. http://dx.doi.org/10.37811/cl_rcm.v4i2.119

Cabrera, L. (2020). Efectos del coronavirus en el sistema de enseñanza: aumenta la desigualdad de oportunidades educativas en España. Revista de Sociología de la Educación (RASE), 13(2), 114-139. http://dx.doi.org/10.7203/RASE.13.2.17125

Cabrera, L., Pérez, C. N. y Santana, F. (2020). ¿Se incrementa la desigualdad de oportunidades educativas en la enseñanza primaria con el cierre escolar por el coronavirus?. International Journal of Sociology of Education, Special Issue: COVID-19 Crisis and Socioeducative Inequalities and Strategies to Overcome them, 27-52. http://dx.doi.org/10.17583/rise.2020.5613 
Calviño, N. (2020). Las medidas de política económica en el contexto de la COVID-19. Economistas, (170), 8-15. Recuperado de https://privado.cemad.es/revistas/online/Revistas/ECONOMISTAS\%20 Num\%20170\%20A4\%20.pdf/187

Carnicero, J. (2020). Gobernanza y crisis del COVID-19. New Medical Economics. Recuperado de https:// www.newmedicaleconomics.es/gestion/gobernanza-y-crisis-del-covid-19

Colom, C. (2020). Las brechas digitales que deben preocuparnos y ocuparnos. Ekonomiaz, Revista Vasca de Economía, (98), 350-353. Recuperado de https://www.euskadi.eus/web01-a2reveko/es/ k86aEkonomiazWar/ekonomiaz/downloadPDF?R01HNoPortal=true\&idpubl=95\&registro=20

Conselleria d'Agricultura, Desenvolupament Rural, Emergència Climàtica i Transició Ecològica. (2021). Estadístiques agrícoles. Recuperado de http://agroambient.gva.es/va/estadistiques-agricoles

Conselleria d'Economia Sostenible, Sectors Productius, Comerç i Treball. (2021). Portal Estadístico de la Generalitat Valenciana. Recuperado de http://pegv.gva.es/es/inicio

Conselleria de Sanitat Universal i Salut Pública. (2021). Información estadística sobre coronavirus en la Comunidad Valenciana. Recuperado de http://coronavirus.san.gva.es/es/estadisticas

Díez, E. J. y Gajardo, K. (2020). Educar y evaluar en tiempos de coronavirus: la situación en España. Multidisciplinary Journal of Educational Research, 10(2), 102-134. https://doi.org/10.17583/ remie. 2020.5604

Espí, A. (2020). Pandemia de la COVID-19. Impacto del coronavirus en el municipio de Los Montesinos (Alicante), marzo a junio de 2020. Recuperado de http://www.losmontesinos.es/wp-content/ uploads/2020/12/Libro-PANDEMIA-COVID-19-Los-Montesinos-2020.pdf

Farinós, J. (2005). Nuevas formas de gobernanza para el desarrollo sostenible del espacio relacional. Ería, (67), 219-235. Recuperado de https://reunido.uniovi.es/index.php/RCG/article/view/1514

Farinós, J. (2008). Gobernanza territorial para el desarrollo sostenible: estado de la cuestión y agenda. Boletín de la Asociación de Geógrafos Españoles, (46), 11-32. Recuperado de https://www.bage.agegeografia.es/ojs/index.php/bage/article/view/668

Farinós, J. y González, M. (2021). La gobernanza territorial como concepto, proceso y resultado. En A. Romero y A. Alejo (Dirs.), Panorama de la Gobernanza. Perspectivas y Retos para su Estudio en Iberoamérica (pp. 147-168). Valencia: Tirant lo Blanch.

Federación Española de Municipios y Provincias [FEMP]. (2020). Medidas económicas extraordinarias para paliar los efectos económicos del coronavirus. Recuperado de http://www.femp.es/sites/default/ files/multimedia/np-medidas_de hacienda_femp_junta_de_portavoces_2 abril_2020_1.pdf

Garamendi, A. (2020). La economía española y su tejido productivo: la resiliencia, el valor para superar

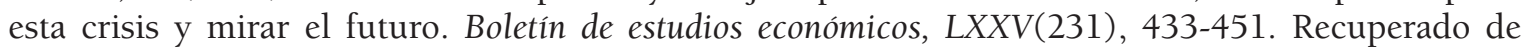
https://issuu.com/deustobusinessalumni/docs/boletin_231

García, N. (2020). Análisis del impacto de la crisis del COVID-19 sobre el comportamiento de compra (Trabajo final de grado). Universitat Politècnica de Catalunya. Barcelona.

García, N., Rivero, M. L. y Guerra, J. (2020). Brecha digital en tiempo del COVID-19. Hekademos Revista Educativa Digital, (28), 76-85. Recuperado de https://www.hekademos.com/index.php/hekademos/ article/view/9

Gascón, J. (2020). COVID-19, estado de emergencia y agricultura familiar en España: mercados campesinos en Barcelona y huertos de autoconsumo en Alcaine (Teruel). AGER: Revista de Estudios sobre Despoblación y Desarrollo Rural, (30), 177-206. http://dx.doi.org/10.4422/ager.2020.13

Giglia, Á. (2020). Repensar las ciudades desde el encierro doméstico. En G. C. Delgado y D. López (Eds.), Las ciudades ante el COVID-19: nuevas direcciones para la investigación urbana y las políticas públicas (pp. 294-303). http://dx.doi.org/10.5281/zenodo.3894075

González, F., Armesto, J. F., Sánchez, P. y Lago, S. (2020). Impacto económico del COVID-19 en una economía regional: el caso del confinamiento para Galicia. Munich Personal RePEc Archive, (100002). Recuperado de https://mpra.ub.uni-muenchen.de/100002/

González, J. M. y Piñeira, M. J. (2020). La ciudad desigual en Palma (Mallorca): geografía del confinamiento durante la pandemia de la COVID-19. Boletín de la Asociación de Geógrafos Españoles, (87), 1-42. http://dx.doi.org/10.21138/bage.2998 
Grima, N., Corcoran, W., Hill-James, C., Langton, B., Sommer, H. y Fisher, B. (2020). The importance of urban natural areas and urban ecosystem services during the COVID-19 pandemic. PLoS ONE, 15(12), 1-13. http://dx.doi.org/10.1371/journal.pone.0243344

Hermosilla, J. (Coord.). (2021). Estrategias para el empleo desde el territorio valenciano. Valencia: Publicacions de la Universitat de València.

Hermosilla, J. y Membrado, J. C. (Coord.). (2018). Estudios comarcales de la provincia de València. El Camp de Túria. Valencia: Publicacions de la Universitat de València y Diputació de València.

Hermosilla, J., Morales, Á., González, T. y Mayordomo, S. (2018). Plan Estratégico Participado Riba-roja de Túria (2017-2025). Valencia: Publicacions de la Universitat de València.

Honey-Rosés, J., Anguelovski, I., Chireh, V. K., Daher, C., Konijnendijk, C., Litt, J. S. ... y Nieuwenhuijsen, M. J. (2020). The impact of COVID-19 on public space: an early review of the emerging questions design, perceptions and inequities. Cities \& Health. http://dx.doi.org/10.1080/23748834.2020.1780074

Hui, D. S., Azhar, E. I., Madani, T. A., Ntoumi, F. Kock, R., Dar, O., ... y Petersen, E. (2020). The continuing 2019-nCoV epidemic threat of novel coronaviruses to global health - The latest 2019 novel coronavirus outbreak in Wuhan, China. International Journal of Infectious Diseases, (91), 264266. http://dx.doi.org/10.1016/j.ijid.2020.01.009

Izquierdo, G. y Vicente, N. (2020). La empresa española como protagonista de la reactivación: acciones y cambios necesarios desde una perspectiva estratégica. Economistas, (170), 16-28. Recuperado de https://privado.cemad. es/revistas/online/Revistas/ECONOMISTAS\%20Num\%20170\%20A4\%20.pdf/187

Jordán, J. M. y Sorribes, J. (1994). L'àrea metropolitana de València i el procés d'urbanització del Camp de Túria. En Congrés d'Estudis Comarcals del Camp de Túria, Segon Congrés d'Estudis Comarcals del Camp de Túria: ponències i comunicacions (pp. 19-23). Benaguasil: Institut d'Estudis Comarcals del Camp de Túria, Tandem.

Joshi, A. Vinay, M. y Bhaskar, P. (2021). Impact of coronavirus pandemic on the Indian education sector: perspectives of teachers on online teaching and assessments. Interactive Technology and Smart Education, 18(2), 205-226. http://dx.doi.org/10.1108/ITSE-06-2020-0087

Kavan, S. (2021). Selected social impacts and measures resulting from the Covid-19 epidemic in the Czech Republic on the specific example of the South Bohemian Region. Health E Social Care in the Community, 29(5), e224-e231. http://dx.doi.org/10.1111/hsc.13272

Llorente-Adán, J. Á. y Ruíz-Tricio, J. F. (2020). El desarrollo rural a partir de la gobernanza territorial en tiempos del coronavirus (Ocón, La Rioja, España). TERRA. Revista de Desarrollo Local, (7), 72-95. http://dx.doi.org/10.7203/terra.7.17533

López, C. (2020). El papel de las entidades locales ante la pandemia. El País. Recuperado de https://elpais. com/economia/2020/05/05/finanzas_a_las_9/1588699518_916371.html

Martí-Costa, M. (Dir.), Barres, R. y Termes, A. (2020). La governança de l'emergència complexa: la covid-19. Actuacions, adaptació organitzativa i innovacions de l'Ajuntament de Barcelona. Barcelona: Gerència Municipal de l'Ajuntament de Barcelona. Recuperado de http://hdl.handle.net/11703/122612

Maza, A. y Villarreal, A. (2020). Impacto del COVID-19 en el empleo informal en ciudades latinoamericanas: elementos para el diseño de políticas públicas. En G. C. Delgado y D. López (Eds.), Las ciudades ante el COVID-19: nuevas direcciones para la investigación urbana y las políticas públicas (pp. 266-275). http://dx.doi.org/10.5281/zenodo.3894075

Medina, M. A. (2020). Nueva movilidad y miedo al contagio: el transporte público, ante la mayor crisis de su historia. El País. Recuperado de https://elpais.com/clima-y-medio-ambiente/2020-12-30/nuevamovilidad-y-miedo-al-contagio-el-transporte-publico-ante-la-mayor-crisis-de-su-historia.html

Molina, A., de Pablo, J., Milán, J. y Caparrós, J. L. (2020). COVID-19. ¿Oportunidad para el mundo rural en España? Una reflexión. Economistas, (170), 167-182. Recuperado de https://privado.cemad. es/revistas/online/Revistas/ECONOMISTAS\%20Num\%20170\%20A4\%20.pdf/187

Morales, A. J., Morales, M., Barberá, R. y Herreros, R. (2020). Catàleg d’Arbratge Monumental i Singular de Riba-roja de Túria. Volum 2. Riba-roja de Túria: Publicacions de l'Ajuntament de Riba-roja de Túria.

Naciones Unidas. (2020). Documento de políticas: la COVID-19 en un mundo urbano. Recuperado de https:// www.un.org/sites/un2.un.org/files/covid-19_in_an_urban_world_spanish.pdf

Organización Mundial de la Salud [OMS]. (2020). Fortalecimiento de la preparación para la COVID-19 en las ciudades y otros entornos urbanos. Orientaciones provisionales para las autoridades locales. Recuperado de 
https://apps.who.int/iris/bitstream/handle/10665/332039/WHO-2019-nCoV-Urban_preparedness-2020.1spa.pdf? sequence $=1 \&$ isAllowed $=\mathrm{y}$

Organización Mundial de la Salud [OMS]. (2021). Cronología de la respuesta de la OMS a la COVID-19. Recuperado de https://www.who.int/es/news/item/29-06-2020-covidtimeline

Oubiña, J. (2020). Transformación digital, redes sociales y comercio electrónico en la estrategia empresarial frente a la COVID-19. Economistas, (170), 140-155. Recuperado de https://privado.cemad.es/revistas/ online/Revistas/ECONOMISTAS\%20Num\%20170\%20A4\%20.pdf/187

Oxfam Intermón (2021). Superar la pandemia y reducir la desigualdad. Cómo hacer frente a la crisis sin repetir errores. Recuperado de https://f.hubspotusercontent20.net/hubfs/426027/Oxfam-Website/oiinformes/superar-covid-reducir-desigualdad-oxfam-intermon.pdf

Paisaje Transversal. (2020). La ciudad como escenario global de la pandemia de la COVID-19. Recuperado de https://paisajetransversal.org/2020/04/ciudad-territorio-escenario-global-pandemia-crisissanitaria-covid-19-coronavirus-confinamiento-urbanismo/

Ponce, I. (2020). La solidaridad en los tiempos del coronavirus. En Grupo de Investigación Corona Social (Coord.), COVID-19 Caos 2.0. Ensayos desconfinados. Ideas de debate para la post pandemia (pp. 123-138). Recuperado de https://dialnet.unirioja.es/descarga/libro/765841.pdf

Pont-Vidal, J. (2020). Delineamientos de desarrollo local en tiempos de incertidumbre: oportunidad para otro tipo de planteamientos. TERRA. Revista de Desarrollo Local, (7), 119-146. http://dx.doi. org/10.7203/terra.7.18160

Prem, K., Liu, Y., Russell, T. W., Kucharski, A., Eggo, R. M., Davies, N. ... y Klepac, P. (2020). The effect of control strategies to reduce social mixing on outcomes of the COVID-19 epidemic in Wuhan, China: a modelling study. Lancet Public Health, 5(5), 261-270. http://dx.doi.org/10.1016/S2468$\underline{2667(20) 30073-6}$

Presidencia del Gobierno de España. (2020a). Coronavirus COVID-19. Plan de desescalada. Recuperado de https://www.lamoncloa.gob.es/consejodeministros/Paginas/enlaces/280420-enlace-desescalada.aspx

Presidencia del Gobierno de España. (2020b). Plan de Recuperación, Transformación y Resiliencia. Recuperado de https://portal.mineco.gob.es/RecursosArticulo/mineco/ministerio/ficheros/plan_de_ recuperacion.pdf

Romero, J. (2006). España inacabada. Valencia: Publicacions de la Universitat de València.

Romero, J. (2020). Gobernanza territorial y vieja normalidad política en España. A propósito del modelo de federalismo incompleto y disfuncional. En J. J. Moreno-Fuentes y E. del Pino (Eds.), Las transformaciones territoriales y sociales del estado en la edad digital. Libro homenaje a Luis Moreno (pp. 123-156). Madrid: Centro de Estudios Políticos y Constitucionales.

Rozga, R. E. y Hernández, R. (2019). Las ciudades y territorios inteligentes en el contexto de las políticas públicas territoriales; relación entre gobernanza territorial y resiliencia. En M. V. Santana, R. M. Sánchez, F. Zepeda, J. R. Calderón y G. Santana (Coord.), Transformaciones territoriales en México y Polonia: Vulnerabilidad, resiliencia y ordenación territorial (pp. 621-653). Recuperado de http:// ri.uaemex.mx/handle/20.500.11799/104812

Sandín, B., Valiente, R. M., García-Escalera, J. y Chorot, P. (2020). Impacto psicológico de la pandemia de COVID-19: Efectos negativos y positivos en población española asociados al periodo de confinamiento nacional. Revista de Psicopatología y Psicología Clínica, 25(1), 1-22. http://dx.doi.org/10.5944/ rppc. 27569

Servei Valencià d'Ocupació i Formació [LABORA]. (2021a). Estadísticas de Contratación Registrada. Recuperado de http://labora.gva.es/es/estadisticascontratacionciudadano

Servei Valencià d'Ocupació i Formació [LABORA]. (2021b). Estadísticas SISPE - Demandantes Activos Parados. Recuperado de http://labora.gva.es/es/estadisticassispehtml

United Cities and Local Governments [UCLG], Metropolis y LSE Cities. (2020). Monitores de la COVID-19 relevantes para la gobernanza urbana y regional. Recuperado de https://www.uclg.org/ sites/default/files/egi_report_es.pdf

Venter, Z. S., Barton, D. N., Gundersen, V., Figari, H. y Nowell, M. (2020). Urban nature in a time of crisis: recreational use of green space increases during the COVID-19 outbreak in Oslo, Norway. Environmental Research Letters, 15(10). http://dx.doi.org/10.1088/1748-9326/abb396 